\title{
Mineralogical and oxygen isotopic study of a new ultrarefractory inclusion in the Northwest Africa 3118 CV3 chondrite
}

\author{
Yong XIONG ${ }^{1}$, Ai-Cheng ZHANG (D* ${ }^{* 1,2}$, Noriyuki KAWASAKI ${ }^{3}$, Chi MA (iD ${ }^{4}$, Naoya SAKAMOTO ${ }^{5}$, \\ Jia-Ni CHEN ${ }^{1}$, Li-Xin $\mathrm{GU}^{6}$, and Hisayoshi YURIMOTO ${ }^{3,5}$ \\ ${ }^{1}$ State Key Laboratory for Mineral Deposits Research, School of Earth Sciences and Engineering, Nanjing University, \\ Nanjing 210023, China \\ ${ }^{2}$ CAS Center for Excellence in Comparative Planetology,Hefei, China \\ ${ }^{3}$ Department of Natural History Sciences, Hokkaido University, Sapporo 060-0810, Japan \\ ${ }^{4}$ Division of Geological and Planetary Sciences, California Institute of Technology, Pasadena, California 91125, USA \\ ${ }^{5}$ Isotope Imaging Laboratory, Creative Research Institution Sousei, Hokkaido University, Sapporo 001-0021, Japan \\ ${ }^{6}$ Institute of Geology and Geophysics, Chinese Academy of Sciences, Beijing 100029, China \\ *Corresponding author. E-mail: aczhang@nju.edu.cn
}

(Received 27 March 2020; revision accepted 09 September 2020)

\begin{abstract}
Calcium-aluminum-rich inclusions (CAIs) are the first solid materials formed in the solar nebula. Among them, ultrarefractory inclusions are very rare. In this study, we report on the mineralogical features and oxygen isotopic compositions of minerals in a new ultrarefractory inclusion CAI 007 from the CV3 chondrite Northwest Africa (NWA) 3118. The CAI 007 inclusion is porous and has a layered (core-mantle-rim) texture. The core is dominant in area and mainly consists of Y-rich perovskite and Zr-rich davisite, with minor refractory metal nuggets, $\mathrm{Zr}$,Sc-rich oxide minerals (calzirtite and tazheranite), and $\mathrm{Fe}$-rich spinel. The calzirtite and tazheranite are closely intergrown, probably derived from a precursor phase due to thermal metamorphism on the parent body. The refractory metal nuggets either exhibit thin exsolution lamellae of $\mathrm{Fe}$,Ni-dominant alloy in Os,Ir-dominant alloy or are composed of $\mathrm{Os}, \mathrm{Ir}, \mathrm{Ru}, \mathrm{Fe}$-alloy and $\mathrm{Fe}, \mathrm{Ni}, \mathrm{Ir}$-alloy with troilite, scheelite, gypsum, and molybdenite. The later four phases are apparently secondary minerals. The $\mathrm{Zr}$, $\mathrm{Sc}, \mathrm{Y}$-rich core is surrounded by a discontinuous layer of closely intergrown hibonite and spinel. The CAIs are rimmed by Fe-rich spinel and Al-rich diopside. Perovskite has high concentrations of the most refractory rare earth elements (REEs) but is relatively depleted in the moderately refractory and volatile REEs, consistent with the ultrarefractory REE pattern. Based on this unusual $\mathrm{Zr}, \mathrm{Sc}, \mathrm{Y}$-rich mineral assemblage, the layered distribution in CAI 007, and the REE concentrations in perovskite, we suggest that CAI 007 is an ultrarefractory inclusion of condensation origin. In CAI 007, hibonite, spinel, and probably Al-rich diopside are ${ }^{16} \mathrm{O}$-rich $\left(\Delta^{17} \mathrm{O} \sim 22 \%\right.$ ) whereas perovskite and davisite are ${ }^{16} \mathrm{O}$-poor $\left(\Delta^{17} \mathrm{O} \sim-3 \%\right.$ ). Such oxygen isotope heterogeneity suggests that the UR inclusion formed in the various degrees of ${ }^{16} \mathrm{O}$-rich nebular setting or was originally ${ }^{16} \mathrm{O}$-rich and then experienced oxygen isotope exchange with ${ }^{16} \mathrm{O}$-poor fluid on the $\mathrm{CV} 3$ chondrite parent body.
\end{abstract}

\section{INTRODUCTION}

Calcium-aluminum-rich inclusions (CAIs) in chondrites are the first solids formed in the solar system (Connelly et al. 2012) and may be divided into a number of groups based on their rare earth element
(REE) patterns (Mason and Martin 1977). Among various groups of CAIs, the group II REE pattern is of great interest because it is closely related to the condensation process in the solar nebula and that commonly observed in chondrites. The group II REE pattern is mainly featured by a uniform enrichment in 
moderately volatile REEs (La-Sm and Tm) and depletions in both the most refractory REEs (Gd-Lu except $\mathrm{Tm}$ and $\mathrm{Yb}$ ) and the most volatile REEs (Eu and $\mathrm{Yb}$ ). Such a REE pattern was thought to be produced by gas-solid condensation after ultrarefractory (UR) CAIs have been condensed and removed from the solar nebular gas (Boynton 1975). Recently, an investigation based on stable isotopic fractionations of REEs in group II CAIs suggested that the group II REE pattern might have formed by more complex processes, involving rapid partial evaporation and condensation of precursors with chondritic composition and the presence of evaporative solid residue enriched in the most refractory REEs $(\mathrm{Hu}$ et al. 2020). This means that UR CAIs, which are enriched in the most refractory REEs and depleted in both moderately and most volatile REEs, might be either the most refractory condensation materials in the solar nebula (Boynton 1975) or solid residues from incomplete evaporation of precursors with chondritic REE composition (Hu et al. 2020). Ultrarefractory CAIs have been reported in a few primitive chondrites, based on the assumption that the CAIs enriched in $\mathrm{Zr}$,Sc-rich minerals have UR REE patterns (Palme et al. 1982; Simon et al. 1996; El Goresy et al. 2002; Ushikubo et al. 2004; Ivanova et al. 2012; Ma et al. 2013, 2014; Krot et al. 2019a; Ma et al. [2020]; and references therein), which was confirmed recently by synchrotron radiation X-ray fluorescence spectroscopic analyses (Genzel et al. 2020).

Ultrarefractory CAIs deserve comprehensive mineralogical, chemical, and isotopic investigations, given that they are the refractory materials that have formed at the highest temperature stage in the solar system. However, UR CAIs are very rare. Some of them are very small in size and their constituent minerals are also usually very fine-grained (Ma et al. 2013, 2020; Krot et al. 2019a). Some UR CAIs have experienced partial melting, making it difficult to constrain the origin of UR inclusions (condensate or evaporation solid residue). Krot et al. (2019a) performed a comprehensive study on the petrography, mineral assemblage, mineral chemistry, and oxygen isotope composition of 25 UR CAIs, which include most of the UR CAIs found in various chondrites to date. As shown in Krot et al. (2019a) and references therein, UR CAIs usually contain various refractory minerals (such as $\mathrm{Zr}$,Sc-rich minerals and refractory metals) and show a large variation in oxygen isotopic compositions, especially in the chondrites that have probably experienced thermal metamorphism on the parent bodies.

Here, we describe the mineralogy, petrography, REE contents, and oxygen isotopic composition of UR CAI 007 from the CV3 meteorite Northwest Africa (NWA) 3118. We also discuss the formation history of this UR inclusion and the potential significance to the variation of oxygen isotopic compositions among different minerals.

\section{ANALYTICAL METHODS}

The petrography of the $\mathrm{Ca}, \mathrm{Al}$-rich inclusion CAI 007 in NWA 3118 was observed using the Zeiss Supra55 field emission scanning electron microscope (FE-SEM) with backscattered electron (BSE) imaging mode at Nanjing University, Nanjing, China. The instrument was operated at an accelerating voltage of $15 \mathrm{kV}$. X-ray elemental mapping was performed with an energy-dispersive spectrometer (EDS) installed on the JSM 7000F FE-SEM at Hokkaido University, Sapporo, Japan.

Quantitative compositional analyses of major and minor elements in oxide and silicate minerals were conducted with the JEOL 8100 electron probe microanalyzer (EPMA) with five wavelength-dispersive spectrometers (WDS) at Nanjing University. Given that most of the minerals in CAI 007 are fine-grained $(<10 \mu \mathrm{m})$, the instrument was operated at an accelerating $10 \mathrm{kV}$ and a focused beam of $10 \mathrm{nA}$. The concentrations of $\mathrm{Si}, \mathrm{Ti}, \mathrm{Zr}, \mathrm{Al}, \mathrm{Cr}, \mathrm{Sc}, \mathrm{Y}, \mathrm{Mg}, \mathrm{Fe}, \mathrm{Mn}$, $\mathrm{Ca}, \mathrm{Na}$, and $\mathrm{K}$ were calibrated with both natural and synthetic standards. Peak and background counting times were 20 and $10 \mathrm{~s}$ for most elements, respectively, except $\mathrm{Na}$ and $\mathrm{K}$ (10 and $5 \mathrm{~s}$, respectively). All data were processed with the ZAF correction procedure supplied with the JEOL microprobe. The amounts of $\mathrm{Ti}^{3+}$ in pyroxene with $\mathrm{TiO}_{2} \geq 4 \mathrm{wt} \%$ and calzirtite ([Ca, $\mathrm{Zr}, \mathrm{Ti}]_{9} \mathrm{O}_{16}$ ) were calculated based on ideal stoichiometry of pyroxene and calzirtite, respectively, and an assumption that titanium is the only element with various valences.

Rare earth elements in perovskite and hibonite were measured using JEOL 8530 field-emission EPMA at Nanjing University. The measurements were made at an accelerating voltage of $15 \mathrm{kV}$ and a beam current of $20 \mathrm{nA}$ with a focused beam. Peak and background positions of different REE elements were chosen based on qualitative analysis of natural monazite. Upper and lower background positions relative to the elemental peaks vary by $1-5 \mathrm{~mm}$ from element to element. Peak and background counting times were 20 and $10 \mathrm{~s}$ for all REEs. Concentrations of $\mathrm{La}, \mathrm{Ce}, \mathrm{Pr}, \mathrm{Nd}, \mathrm{Sm}, \mathrm{Eu}, \mathrm{Ga}$, $\mathrm{Tb}, \mathrm{Dy}, \mathrm{Ho}, \mathrm{Er}, \mathrm{Tm}, \mathrm{Yb}$, and $\mathrm{Lu}$ were calibrated with REE-doped synthetic phosphate standards. The detection limits are $0.05 \mathrm{wt} \%$ for $\mathrm{La}_{2} \mathrm{O}_{3}, 0.04 \mathrm{wt} \%$ for $\mathrm{Ce}_{2} \mathrm{O}_{3}, 0.07 \mathrm{wt} \%$ for $\mathrm{Pr}_{2} \mathrm{O}_{3}, 0.07 \mathrm{wt} \%$ for $\mathrm{Nd}_{2} \mathrm{O}_{3}$, $0.08 \mathrm{wt} \% \mathrm{Sm}_{2} \mathrm{O}_{3}, 0.08 \mathrm{wt} \%$ for $\mathrm{Eu}_{2} \mathrm{O}_{3}, 0.1 \mathrm{wt} \%$ for $\mathrm{Gd}_{2} \mathrm{O}_{3}, \quad 0.09 \mathrm{wt} \%$ for $\mathrm{Tb}_{2} \mathrm{O}_{3}, \quad 0.1 \mathrm{wt} \%$ for $\mathrm{Dy}_{2} \mathrm{O}_{3}$, $0.1 \mathrm{wt} \%$ for $\mathrm{Ho}_{2} \mathrm{O}_{3}, 0.11 \mathrm{wt} \%$ for $\mathrm{Er}_{2} \mathrm{O}_{3}, 0.09 \mathrm{wt} \%$ for $\mathrm{Tm}_{2} \mathrm{O}_{3}, 0.15 \mathrm{wt} \%$ for $\mathrm{Yb}_{2} \mathrm{O}_{3}$, and $0.16 \mathrm{wt} \%$ for $\mathrm{Lu}_{2} \mathrm{O}_{3}$. 
Structural characterization of minerals in CAI 007 was performed using electron backscatter diffraction (EBSD) and transmission electron microscopy. Before obtaining EBSD patterns, the sample was polished using a vibromet instrument with silica suspension and then carbon-coated. The EBSD patterns of minerals were obtained using an Oxford EBSD detector attached to the JEOL JSM-6490 SEM instrument at Nanjing University. The EBSD detector was controlled by Aztec software. An accelerating voltage of $20 \mathrm{kV}$ and a beam current of $4 \mathrm{nA}$ were used for collecting EBSD patterns. The EBSD patterns were indexed with the HKL data set of minerals and the index quality was evaluated based on the "mean angular deviation" (MAD) values and manual check. In this study, the indexed results with MAD values of $<1$ are considered desirable for accurate solutions.

Two transmission electron microscopy (TEM) foils containing $\mathrm{Zr}$,Sc-rich oxides and refractory metal nuggets (RMNs), respectively, were prepared with focused ion beam (FIB) system at the Institute of Geology and Geophysics, Chinese Academy of Sciences, Beijing, China. The FIB cutting was conducted using Zeiss Auriga Compact dual beam instrument equipped with an Omniprobe AutoProbe 200 micromanipulator. Ion milling was carried out with an accelerating voltage of 4$30 \mathrm{kV}$ and various beam currents $(50 \mathrm{pA}-2 \mathrm{nA})$. The final foils are approximately $100 \mathrm{~nm}$ in thickness. The microtextural and mineralogical characterizations of these two foils were performed using FEI Tecnai F20 TEM at Nanjing University. All the TEM observations were performed at $200 \mathrm{kV}$. Conventional bright-field TEM and high-angle annular dark-field (HAADF) imaging were performed to record the petrographic textures of the TEM foils. Selected area electron diffraction and high-resolution TEM images were used to determine mineral structures; meanwhile, energydispersive $\mathrm{X}$-ray analyses were used to determine chemical compositions of minerals in the TEM foils. Xray elemental mapping was also performed for constraining the phases at given regions in the TEM foils.

Oxygen isotope compositions of individual minerals (hibonite, spinel, davisite, perovskite, and Al-rich diopside) in the CAI 007 were measured with the Cameca IMS1280HR ion microprobe at Hokkaido University, with the full analytical procedures reported in Kawasaki et al. (2018). The primary ion beam was mass filtered positive ${ }^{133} \mathrm{Cs}^{+}$ions $(20 \mathrm{keV}, 20 \mathrm{pA})$ with the beam size of $\sim 2 \mu \mathrm{m}$ in diameter. A normal incident electron flood gun was used for the electrostatic charge compensation. The mass resolution $\mathrm{M} / \Delta \mathrm{M}$ for ${ }^{17} \mathrm{O}^{-}$was set at $\sim 6000$, sufficient to separate interfering ${ }^{16} \mathrm{OH}^{-}$. Negative ${ }^{16} \mathrm{O}^{-},{ }^{17} \mathrm{O}^{-}$, and ${ }^{18} \mathrm{O}^{-}$ ions were detected with a multi-collection mode, with a multicollector Faraday cup, an axial electron multiplier, and a multicollector electron multiplier, respectively. The secondary ion intensity of ${ }^{16} \mathrm{O}^{-}$was $0.5-1.5 \times 10^{7}$ cps. Each measurement was conducted with 60 cycles of counting the secondary ions of $4 \mathrm{~s}$. The instrumental mass fractionations were calibrated using Takashima augite $\left(\delta^{18} \mathrm{O}=6.3 \%\right)$ and Russian spinel $\left(\delta^{18} \mathrm{O}=8.5 \%\right.$; Yurimoto et al. 1994) for silicate and oxide minerals, respectively. The reported uncertainties of the individual analyses are expressed in $2 \sigma$, which were estimated by considering both the internal error of each measurement and the uncertainty of the instrumental mass fractionation (assigned as 2SE of repetitive analyses of the standards). After the measurements, all spots were evaluated using FESEM. Data from spots that overlapped undesirable minerals and/or cracks have been rejected.

\section{RESULTS}

\section{Brief Introduction about NWA 3118}

Northwest Africa 3118 is a $5.9 \mathrm{~kg}$ oxidized Allendelike CV3 carbonaceous chondrite found in 2003 (Russell et al. 2005). It contains abundant large chondrules and CAIs (usually larger than $1 \mathrm{~mm}$ in size), which are enclosed in fine-grained Fe-rich matrix (Akos et al. 2014; Matsuda et al. 2019). Many of the chondrules in the NWA 3118 hand specimen appear rust in color. No metal grains were observed on the hand specimen scale. The Fe-rich matrix is composed mainly of platy-shaped ferrous olivine grains $(<10 \mu \mathrm{m}$ in length; Fig. 1a) with minor $\mathrm{Ca}-\mathrm{Fe}$-silicate nodules (hedenbergite and andradite). Granular ferrous olivine grains, which may be chondrule fragments, are also commonly observed in the matrix. Fractures and grain boundaries in chondrules are usually filled by Fe-rich phases. Fe-Mg interdiffusion zones of a few micrometers are commonly observed in olivine grains along grain boundaries and fractures. In some chondrules, pyroxene grains have been partially replaced by ferrous olivine (Fig. 1b; Matsuda et al. 2019). A complex refractory inclusion $(3 N)$, which consists of abundant smaller CAIs with various mineral assemblages including an UR inclusion $(3 \mathrm{~N}-24)$, has been reported in NWA 3118 (Ivanova et al. 2012, 2015; MacPherson et al. 2017; Krot et al. 2019a).

\section{Petrography and Mineralogy of CAI 007}

The UR CAI $007,300 \times 500 \mu \mathrm{m}$ in size, is enclosed by fine, platy-shaped, and granular ferrous olivine grains in the matrix (Fig. 2). It has a core-rim layered structure. The core is dominant in area and consists mainly of perovskite and davisite with minor $\mathrm{Zr}$,Sc-rich oxides, spinel, and RMN (Figs. 2 and 3). The sinuous 


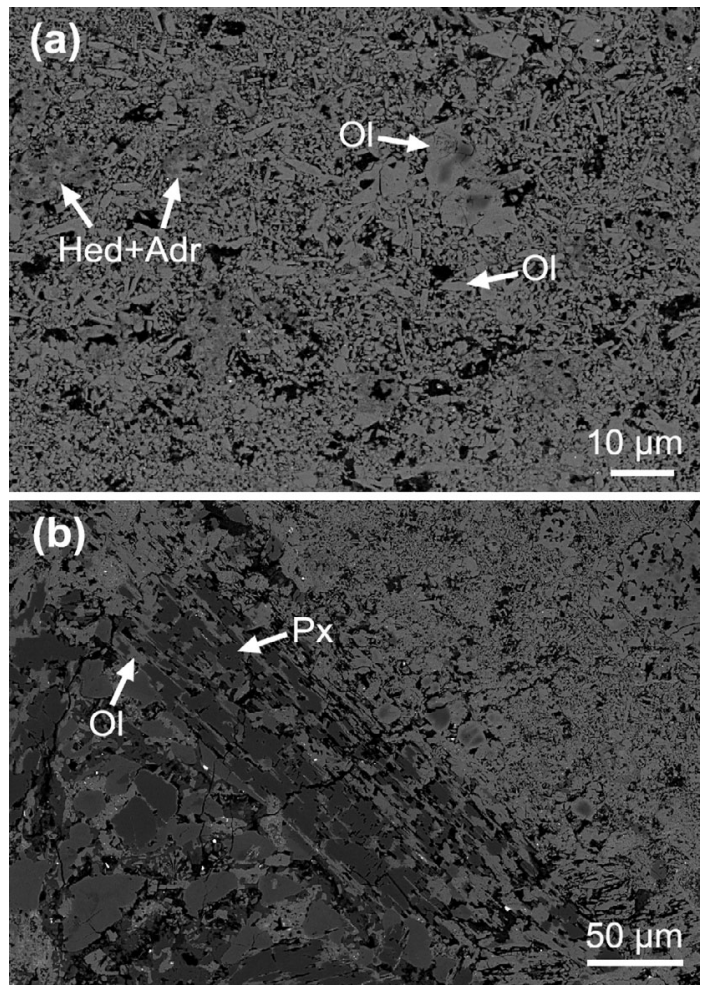

Fig. 1. Backscattered electron image showing a matrix region in NWA 3118. a) Platy ferrous olivine in the matrix. Irregular fragments of granular ferrous olivine grains and aggregates of hedenbergite and andradite are also present. b) Ferrous olivine replacing low-Ca pyroxene in a chondrule. $\mathrm{Ol}=$ olivine; $\mathrm{Px}=$ pyroxene Hed $=$ hedenbergite $; \mathrm{Adr}=$ andradite .

rim is $5-10 \mu \mathrm{m}$ in width and composed mainly of spinel and Al-rich diopside, with Al-rich diopside located on the outside. The rim is porous, especially at the interface between spinel and Al-rich diopside. Some tiny unidentified phases (probably olivine and phosphate?) are also present at the interface between spinel and Alrich diopside. Most of the diopside grains in the rim are approximately $1 \mu \mathrm{m}$ in grain size. Minor amounts of fine-grained ferrous olivine are also observed as overgrowth on Al-rich diopside or as inclusions in the Al-rich diopside layer (Figs. 4b and 4c). A discontinuous layer consisting of hibonite and spinel intergrowth is present along the interface between the core and the rim (Figs. 2 and 3). Fine-grained alteration products are commonly observed in the core and a few regions have been heavily altered. Secondary minerals such as zeolite, grossular, and nepheline have been observed in the altered regions. A few lath-shaped hibonite grains are also observed in the altered regions.

The core of CAI 007 is porous in texture and characterized by the presence of anhedral-to-subhedral perovskite of various grain sizes $(5-20 \mu \mathrm{m})$. The perovskite grains contain high $\mathrm{Y}_{2} \mathrm{O}_{3}$ and $\mathrm{ZrO}_{2}$ (4.8-

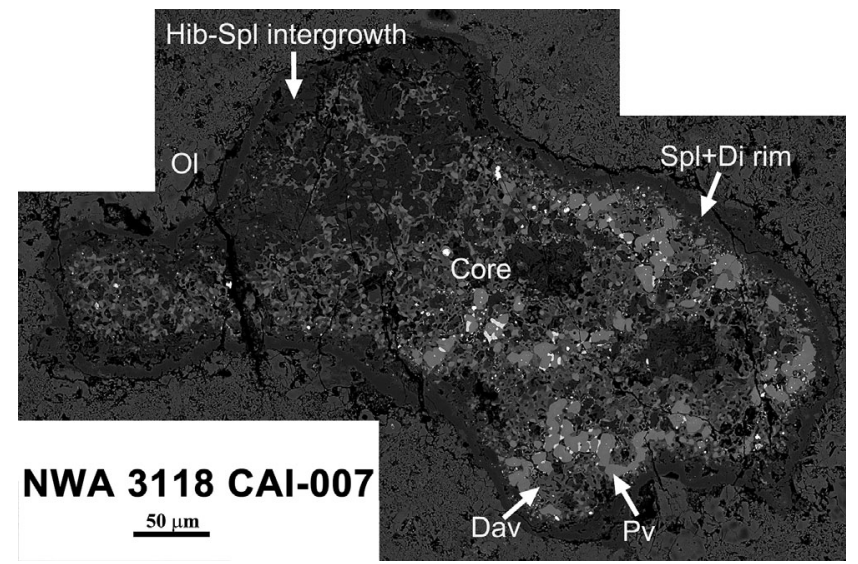

Fig. 2. BSE image of the UR inclusion CAI 007 in NWA 3118. The CAI is porous and has a core-rim layered texture. Its core is dominant and consists mainly of perovskite and davisite with minor $\mathrm{Zr}$,Sc-rich oxides, spinel, and refractory metal nuggets. The rim is sinuous in shape and composed mainly of spinel and Al-rich diopside. A discontinuous layer consisting of hibonite and spinel intergrowth is present along the interface between the core and the rim. Dav = davisite; $\mathrm{Di}=$ Al-rich diopside; $\quad \mathrm{Hib}=$ hibonite; $\mathrm{Pv}=$ perovskite; $\mathrm{Spl}=$ spinel.

$7.1 \mathrm{wt} \%$ and $1.1-1.8 \mathrm{wt} \%$, respectively; Table 1) and no significant difference was observed for the perovskite grains of different grain sizes. These perovskite grains are surrounded by anhedral, fine-grained davisite grains, which appear to be connected with each other. Davisite in CAI 007 contains high $\mathrm{Al}_{2} \mathrm{O}_{3}(25.1-28.0 \mathrm{wt} \%), \mathrm{Sc}_{2} \mathrm{O}_{3}$ $(12.8-15.7 \mathrm{wt} \%), \mathrm{ZrO}_{2}(8.5-14.6 \mathrm{wt} \%)$, and $\mathrm{TiO}_{2}{ }^{\text {tot }}$ $(6.0-8.7 \mathrm{wt} \%)$. The $\mathrm{Y}_{2} \mathrm{O}_{3}$ content in davisite is $0.22-$ $0.68 \mathrm{wt} \%$. Based on the ideal stoichiometry of pyroxene (four cations per six oxygen atoms), the davisite has variable $\mathrm{Ti}^{3+} / \mathrm{Ti}^{\text {tot }}$ values $(0.16-0.70)$ with a mean value of 0.39 (Table 2).

Small, anhedral spinel and $\mathrm{Zr}$,Sc-rich oxide grains $(<6 \mu \mathrm{m})$ are observed as the interstitial phases between perovskite and davisite. The spinel grains have an $\mathrm{Mg \#}$ value varying from 0.34 to 0.53 (Table 3 ). The $\mathrm{Zr}$,Scrich oxide grains are mainly associated with relatively coarse-grained perovskite and enclosed together with perovskite by fine-grained davisite (Figs. 4a and 4b). Our HAADF-STEM observations reveal that a tiny $\mathrm{Zr}$, Sc-rich oxide grain (only one case) is also present as an inclusion in perovskite. High magnification SEM imaging shows that most of the $\mathrm{Zr}$,Sc-rich oxide grains are complex intergrowths of two different phases (Figs. 5b-d), although a few grains contain only one phase (Fig. 5a). Our EBSD and TEM observations reveal that the structures of the brighter phase and the dark phase are consistent with the $I_{1} /$ acd calzirtite and the Fm3m tazheranite (Figs. 6 and 7). Both of them cannot be indexed with the structure of other $\mathrm{Zr}$,Sc-rich 

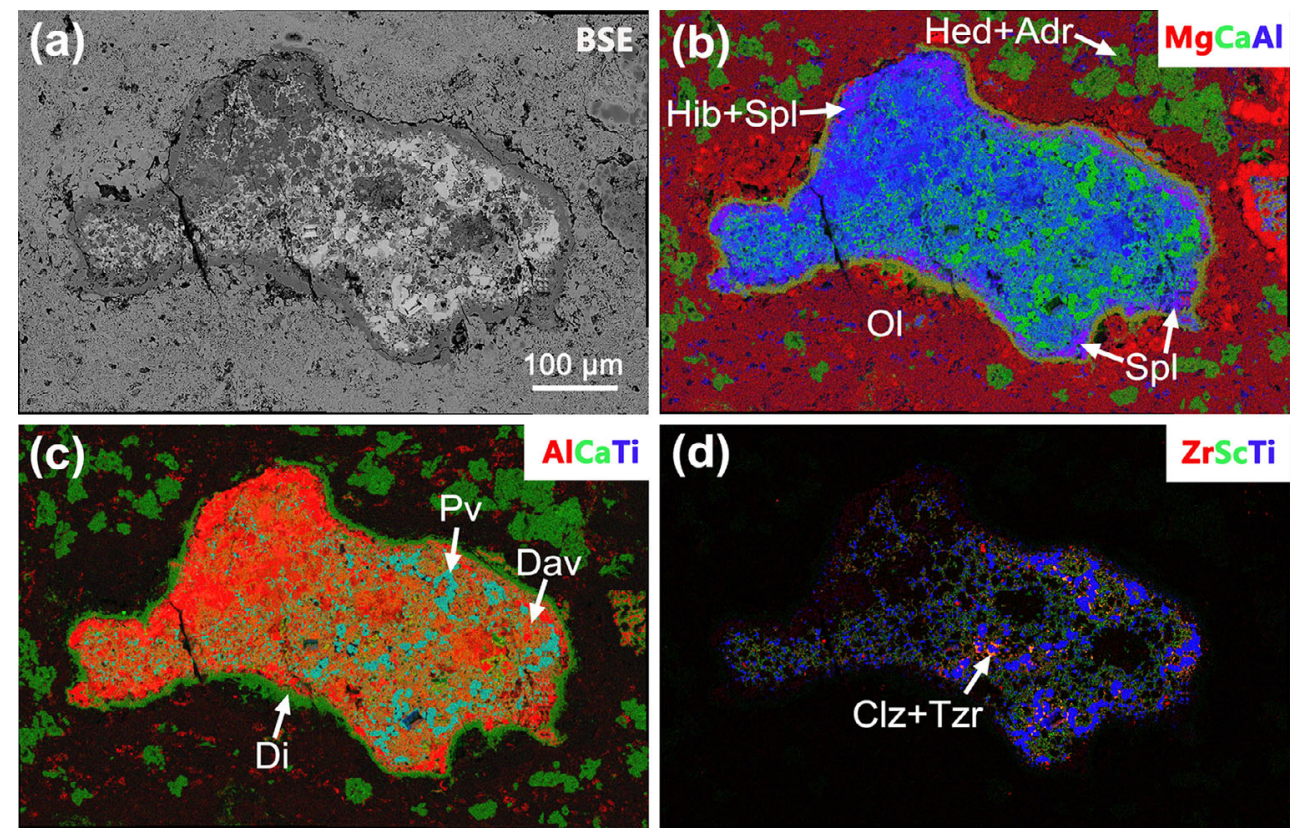

Fig. 3. BSE image and combined X-ray elemental mapping results ( $\mathrm{Mg}, \mathrm{Al}$, or $\mathrm{Zr}$ : red; $\mathrm{Ca}$ or $\mathrm{Sc}$ : green; and $\mathrm{Al}$ or $\mathrm{Ti}$ : blue). $\mathrm{Adr}=$ Andradite; $\mathrm{Clz}=$ calzirtite; $\mathrm{Dav}=$ davisite; $\mathrm{Di}=\mathrm{Al}$-rich diopside; Hed = hedenbergite; Hib $=$ hibonite; $\mathrm{Ol}=\mathrm{olivine}$; $\mathrm{Pv}=$ perovskite; $\mathrm{Spl}=$ spinel; $\mathrm{Tzr}=$ tazheranite. (Color figure can be viewed at wileyonlinelibrary.com.)

phases such as allendeite, kangite, and zirconolite (Ma et al. 2013, 2014; Ma 2020). The compositions of calzirtite grains were determined with EPMA. It has generally homogeneous chemical compositions, 69.2$72.0 \mathrm{wt} \% \quad \mathrm{ZrO}_{2}, \quad 12.0-13.2 \mathrm{wt} \% \quad \mathrm{Sc}_{2} \mathrm{O}_{3}, \quad 7.0-8.5 \mathrm{wt} \%$ $\mathrm{TiO}_{2}{ }^{\text {tot }}$, 4.0-4.1 wt $\%$ CaO, 3.2-3.7 wt $\% \quad \mathrm{Y}_{2} \mathrm{O}_{3}$, and minor other elements (Table 4). Based on 16 oxygen atoms, the chemical formula of calzirtite is $\left(\mathrm{Zr}_{5.281} \mathrm{Sc}_{1.700} \mathrm{Ca}_{0.674} \mathrm{Ti}^{4+}{ }_{0.453} \mathrm{Ti}^{3+}{ }_{0.436} \mathrm{Y}_{0.284} \mathrm{Al}_{0.076} \mathrm{Mg}_{0.047}\right.$ $\left.\mathrm{Fe}_{0.031} \mathrm{Si}_{0.018}\right)_{9} \mathrm{O}_{16}$, where the amount of $\mathrm{Ti}^{3+}$ was calculated based on the ideal stoichiometry of calzirtite $(9$ cations and 16 oxygen atoms). The darker $\mathrm{Zr}$,Sc-rich phase is too small to be analyzed using EPMA with confidence. We determined its composition using TEMEDS (Table 4). The $k$-factors were calibrated roughly by comparing the TEM-EDS and EPMA data for calzirtite. The average composition of the darker $\mathrm{Zr}$,Sc-rich oxide phase is $57.9 \mathrm{wt} \% \quad \mathrm{ZrO}_{2}, \quad 32.5 \mathrm{wt} \% \quad \mathrm{Sc}_{2} \mathrm{O}_{3}, 7.4 \mathrm{wt} \%$ $\mathrm{TiO}_{2}, 1.4 \mathrm{wt} \% \mathrm{CaO}$, and $0.83 \mathrm{wt} \% \mathrm{Y}_{2} \mathrm{O}_{3}$. Based on 1.75 oxygen atoms, the chemical formula of tazheranite is $\left(\mathrm{Sc}_{0.443} \mathrm{Zr}_{0.442} \mathrm{Ti}_{0.087} \mathrm{Ca}_{0.023} \mathrm{Y}_{0.003}\right)_{0.998} \mathrm{O}_{1.75}$. X-ray elemental mapping was performed to show the distribution of elements between calzirtite and tazheranite and the results are shown in Fig. 8.

Numerous RMNs occur as inclusions in other minerals of the core part (Figs. $4 \mathrm{~b}$ and $5 \mathrm{a}$ ). Most of the RMNs are submicron in size and only a few of them are as large as $3-4 \mu \mathrm{m}$. High-magnification SEM observations show that some of the RMNs contain very thin lamellae (Figs. 9a and 9b), and other RMNs also contain other mineral phases (Figs. 9c and 9d). Based on HAADF-STEM observations and TEM-EDS analyses (Fig. 10), Os,Ir-dominant and Fe,Ni,Irdominant alloys are identified, corresponding to osmium and hexaferrum, respectively (Table 5). The osmium grains have an alloy chemical formula $\mathrm{Os}_{36} \mathrm{Ir}_{24} \mathrm{Ru}_{17} \mathrm{Fe}_{16} \mathrm{Re}_{3} \mathrm{Mo}_{2} \mathrm{Ni}_{1}$ while the hexaferrum grains show homogeneous chemical compositions $\mathrm{Fe}_{48} \mathrm{Ni}_{26} \mathrm{Ir}_{22} \mathrm{Os}_{3} \mathrm{Ru}_{2}$. Our observations demonstrate that the minerals closely associated with the refractory metals are scheelite, troilite, gypsum, and molybdenite (Figs. 9 and 10).

Due to the strong alteration, the boundary between the hibonite-spinel intergrowth and the $\mathrm{Zr}, \mathrm{Sc}, \mathrm{Y}$-rich core is obscured. However, in some regions, the hibonite-spinel intergrowth connects directly with the Al-rich diopside rim. The $\mathrm{Mg} \#$ values of spinel in the intergrowth are $0.48-0.69$ (Table 3). The hibonite grains contain a few weight percent of $\mathrm{TiO}_{2}$ and $\mathrm{MgO}$ (3.6-6.3 $\mathrm{wt} \%$ and $2.2-3.3 \mathrm{wt} \%$, respectively; Table 6).

The spinel grains spatially associated with the Alrich diopside rim are relatively $\mathrm{Mg}$-rich $(\mathrm{Mg} \#=0.68$ 0.81; Table 3). The Al-rich diopside grains in the rim are depleted in $\mathrm{ZrO}_{2}$ and $\mathrm{Sc}_{2} \mathrm{O}_{3}$ and contain a few weight percent of $\mathrm{Al}_{2} \mathrm{O}_{3}(1.7-8.0 \mathrm{wt} \%)$ and $\mathrm{TiO}_{2}(0.35$ $1.2 \mathrm{wt} \%$; Table 6). 


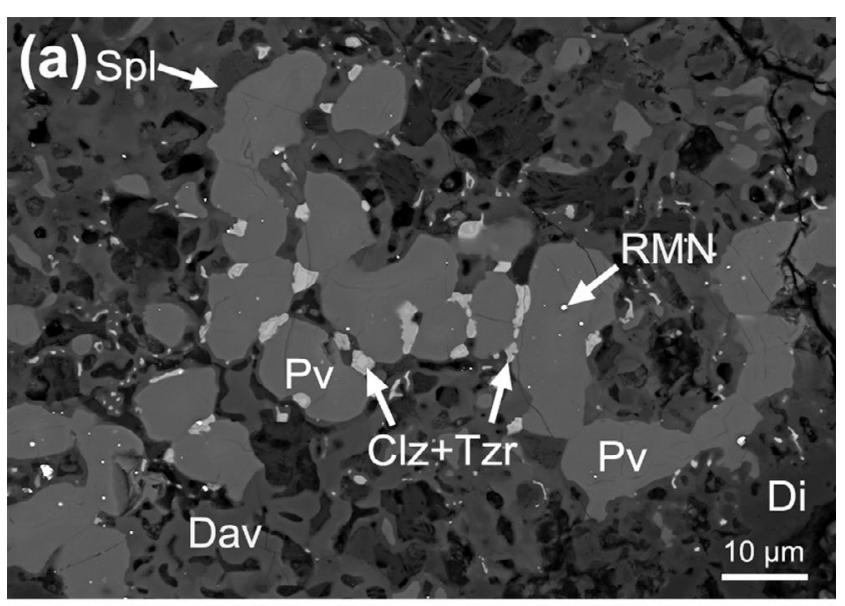

\section{Rare Earth Element Compositions of Minerals in CAI 007}

We tentatively measured REE contents in potentially REE-rich minerals (hibonite, perovskite, and davisite) in CAI 007 using FEG-EPMA. However, the REE concentrations in hibonite and davisite are below the EPMA detection limit (0.04-0.16 wt \%). Only a few most refractory REEs (Gd, Tb, Dy, Ho, Er, and Lu) in perovskite have contents higher than the EPMA detection limit. The analytical results for REE in perovskite are given in Table 1 and plot in Fig. 11.

\section{Oxygen Isotopic Compositions of Minerals in CAI 007}
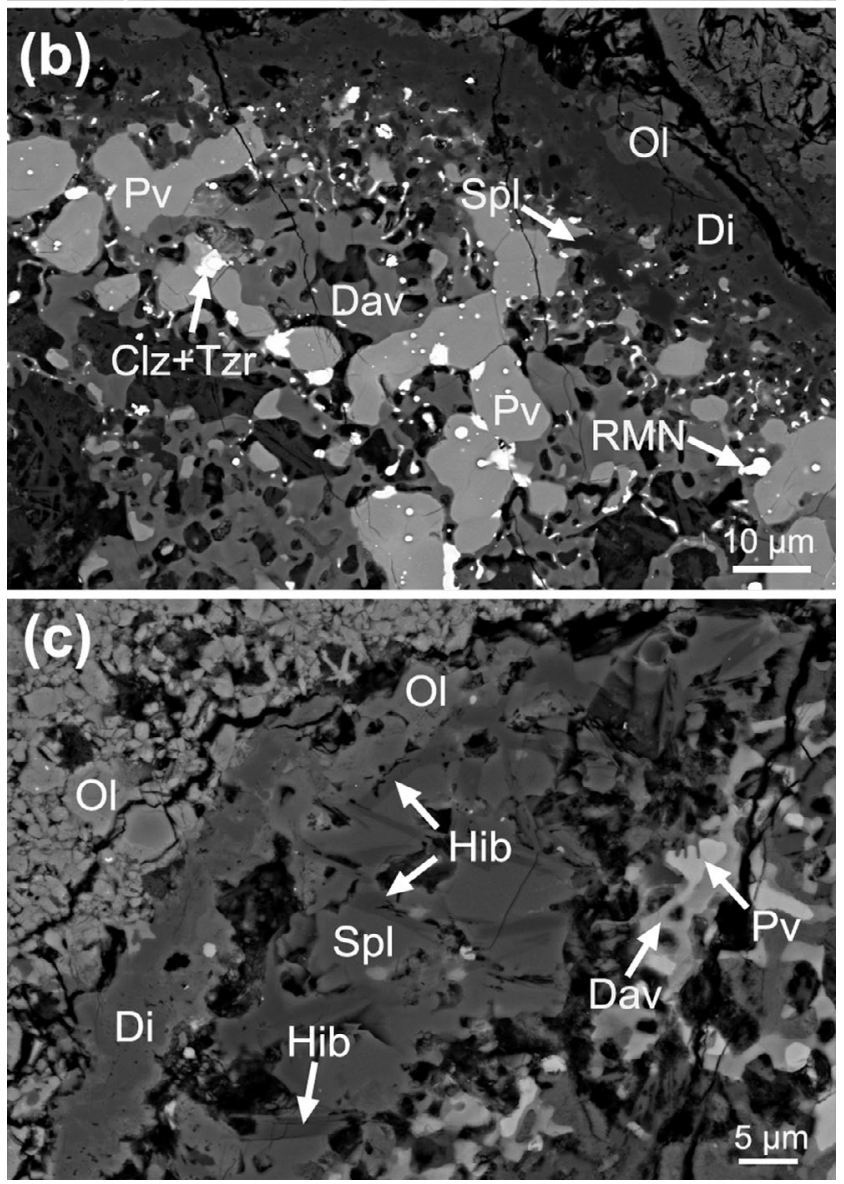

The SIMS oxygen isotopic compositions of individual minerals in CAI 007 are given in Table 7 and plotted in Fig. 12. Only one hibonite grain (in the altered region) was measured in the present study and is ${ }^{16} \mathrm{O}$-rich $\left(\Delta^{17} \mathrm{O} \sim 22 \%\right)$. All the spinel grains from the core, the spinel-hibonite intergrowth, and the rim of CAI 007 are ${ }^{16} \mathrm{O}$-rich $\left(\Delta^{17} \mathrm{O} \sim 22 \%\right.$; Table 7$)$. Both perovskite and davisite in the $\mathrm{Zr}, \mathrm{Sc}, \mathrm{Y}$-rich core are ${ }^{16} \mathrm{O}$ poor $\left(\Delta^{17} \mathrm{O} \sim 3 \%\right.$, respectively). Three spots on Al-rich diopside in the rim were measured and show a relatively large variation in oxygen isotopic composition among different grains $\left(\Delta^{17} \mathrm{O} \sim 20\right.$ to $-12 \%$; Table 7$)$. Figure 13 shows the positions of the two spots (@366 and @367) with less ${ }^{16} \mathrm{O}$-enriched oxygen isotopic feature of Al-rich diopside. Based on the BSE image, the diopside rim contains submicron pores, which might be the main cause of the less ${ }^{16} \mathrm{O}$-enriched oxygen isotopic feature of Al-rich diopside.

\section{DISCUSSION}

\section{Mineralogical Records of Fluid-Assisted Metamorphism in NWA 3118 and CAI 007}

NWA 3118 is a chondrite found in a hot desert, and, therefore, probably has experienced terrestrial weathering. However, such evidence is not commonly observed in NWA 3118. It is reported that FeNi metal in chondrites is very sensitive to terrestrial weathering (Wlotzka 1993). Terrestrial weathering of FeNi metal will lead to the formation of Fe-oxide or Fe-hydroxide phases filling fractures or surrounding relict metal grains (Wlotzka 1993; Zhang and Hsu 2009). FeNi metal grains are not recognized in hand specimen of NWA 3118 and Fe-oxide phases have been widely observed in NWA 3118 (figs. S3 and S5 of Matsuda et al. 2019), suggesting that NWA 3118 may have experienced terrestrial weathering. However, Fe-oxide and Fe-hydroxide veins across the matrix and different 
Table 1. EPMA compositions (wt $\%$ ) of perovskite in CAI-007.

\begin{tabular}{|c|c|c|c|c|c|}
\hline & 1 & 3 & 4 & 5 & 6 \\
\hline $\mathrm{SiO}_{2}$ & 0.07 & 0.04 & bdl & bdl & bdl \\
\hline $\mathrm{TiO}_{2}$ & 53.0 & 53.2 & 51.7 & 52.2 & 52.7 \\
\hline $\mathrm{ZrO}_{2}$ & 1.5 & 1.3 & 1.5 & 1.7 & 1.8 \\
\hline $\mathrm{Al}_{2} \mathrm{O}_{3}$ & 1.4 & 1.2 & 1.7 & 1.7 & 1.5 \\
\hline $\mathrm{Cr}_{2} \mathrm{O}_{3}$ & bdl & bdl & bdl & 0.09 & 0.07 \\
\hline $\mathrm{Sc}_{2} \mathrm{O}_{3}$ & 0.25 & 0.38 & 0.51 & 0.34 & 0.39 \\
\hline $\mathrm{Y}_{2} \mathrm{O}_{3}$ & 5.6 & 4.8 & 7.1 & 6.3 & 6.4 \\
\hline $\mathrm{MgO}$ & 0.08 & 0.03 & bdl & bdl & 0.03 \\
\hline $\mathrm{FeO}$ & 0.70 & 0.33 & 0.58 & 0.5 & 0.19 \\
\hline $\mathrm{MnO}$ & 0.03 & bdl & bdl & bdl & 0.07 \\
\hline $\mathrm{CaO}$ & 36.1 & 36.0 & 35.8 & 35.2 & 35.3 \\
\hline $\mathrm{Na}_{2} \mathrm{O}$ & 0.25 & bdl & bdl & bdl & bdl \\
\hline $\mathrm{K}_{2} \mathrm{O}$ & bdl & 0.02 & 0.03 & bdl & bdl \\
\hline $\mathrm{Gd}_{2} \mathrm{O}_{3}$ & 0.14 & 0.32 & 0.13 & 0.29 & 0.32 \\
\hline $\mathrm{Tb}_{2} \mathrm{O}_{3}$ & bdl & 0.09 & bdl & bdl & bdl \\
\hline $\mathrm{Dy}_{2} \mathrm{O}_{3}$ & 0.24 & 0.32 & 0.50 & 0.43 & 0.40 \\
\hline $\mathrm{Ho}_{2} \mathrm{O}_{3}$ & 0.09 & bdl & 0.18 & 0.25 & 0.29 \\
\hline $\mathrm{Er}_{2} \mathrm{O}_{3}$ & 0.46 & 0.38 & 0.65 & 0.63 & 0.64 \\
\hline $\mathrm{Lu}_{2} \mathrm{O}_{3}$ & 0.21 & 0.38 & bdl & bdl & bdl \\
\hline Total & 100.1 & 98.8 & 100.4 & 99.7 & 100.1 \\
\hline $\mathrm{Si}$ & 0.002 & 0.001 & bdl & bdl & bdl \\
\hline $\mathrm{Ti}$ & 0.928 & 0.941 & 0.909 & 0.921 & 0.926 \\
\hline $\mathrm{Zr}$ & 0.017 & 0.015 & 0.017 & 0.020 & 0.021 \\
\hline $\mathrm{Al}$ & 0.038 & 0.034 & 0.047 & 0.048 & 0.040 \\
\hline $\mathrm{Cr}$ & bdl & bdl & bdl & 0.002 & 0.001 \\
\hline $\mathrm{Sc}$ & 0.005 & 0.008 & 0.010 & 0.007 & 0.008 \\
\hline $\mathrm{Y}$ & 0.069 & 0.061 & 0.089 & 0.079 & 0.08 \\
\hline $\mathrm{Mg}$ & 0.003 & 0.001 & bdl & bdl & 0.001 \\
\hline $\mathrm{Fe}$ & 0.014 & 0.007 & 0.011 & 0.010 & 0.004 \\
\hline $\mathrm{Mn}$ & 0.001 & bdl & bdl & bdl & 0.001 \\
\hline $\mathrm{Ca}$ & 0.904 & 0.909 & 0.898 & 0.887 & 0.887 \\
\hline $\mathrm{Na}$ & 0.011 & bdl & bdl & bdl & bdl \\
\hline $\mathrm{K}$ & bdl & 0.001 & 0.001 & bdl & bdl \\
\hline $\mathrm{Gd}$ & 0.001 & 0.003 & 0.001 & 0.002 & 0.002 \\
\hline $\mathrm{Tb}$ & bdl & 0.001 & bdl & bdl & bdl \\
\hline Dy & 0.002 & 0.002 & 0.004 & 0.003 & 0.003 \\
\hline Ho & 0.001 & bdl & 0.001 & 0.002 & 0.002 \\
\hline $\mathrm{Er}$ & 0.003 & 0.003 & 0.005 & 0.005 & 0.005 \\
\hline $\mathrm{Lu}$ & 0.001 & 0.003 & bdl & bdl & bdl \\
\hline Sum & 2.000 & 1.990 & 1.993 & 1.986 & 1.981 \\
\hline
\end{tabular}

Cations are calculated based on three oxygen atoms. bdl $=$ below detection limit.

components (refractory inclusions and chondrules) are not observed in our study and in previous investigations on NWA 3118 (e.g., Akos et al. 2014; Matsuda et al. 2019). Therefore, we suggest that terrestrial weathering might have not affected the majority of minerals. Instead, many secondary mineralogical features observed in NWA 3118 could be attributed to fluidassisted metamorphism and/or alteration on the parent body of the CV3 chondrite parent body (Brearley and Krot 2013).
NWA 3118 contains the following alteration records (1) platy-shaped ferrous olivine in the matrix and ferrous olivine altering low-Ca pyroxene; (2) $\mathrm{Ca}-\mathrm{Fe}$-silicate phases (hedenbergite and andradite) in the matrix; (3) fine-grained Ca-rich aluminosilicate minerals (zeolite, grossular, and nepheline) in the altered regions in CAI 007 and chondrule mesostasis (fig. S2 of Matsuda et al. 2019); (4) magnetite in chondrules and thin Fe-oxide/ hydroxide veinlets infilling the irregular cracks in silicate minerals (Matsuda et al. 2019); (5) scheelite, gypsum, and molybdenite observed in refractory metal nuggets. Most of these minerals are typical alteration products in oxidized CV3 chondrites (Krot et al. 1995, 1998a, 1998b; Brearley and Krot [2013] and references therein) and have also been observed in other groups of carbonaceous chondrites (e.g., Brearley and Krot 2013; Zhang and Yurimoto 2013; Li et al. 2017). Zeolite is observed in CV chondrite for the first time; however, given that NWA 3118 is a find chondrite, we cannot totally exclude the possibility of terrestrial origin. Gypsum was considered as a product of terrestrial weathering of chondrite (e.g., Lee 1993; Izawa et al. 2010b); however, it was also observed in fall meteorites that experienced no terrestrial weathering (e.g., Izawa et al. 2010a). Given that gypsum shows straight grain boundaries with hexaferrum grains (Fig. 10), in the present study, we cannot exclude the parent-body alteration origin of the gypsum. The magnetite nodules in CVs chondrites were interpreted by Marrocchi et al. (2016) as magmatic origin. The petrographic texture of magnetite in NWA 3118 appears distinctly different from the magnetite nodules described by Marrocchi et al. (2016), which are usually clean in BSE images. However, the magnetite grains in chondrules from NWA 3118 are usually porous in texture (Matsuda et al. 2019). Therefore, we consider that magnetite in NWA 3118 should be of parent-body alteration origin. In previous investigations (El Goresy et al. 1978; MacPherson et al. [1988] and references therein), scheelite and molybdenite have been observed in Fremdlinge (also called opaque assemblage) within CAIs. Many early workers thought that Fremdlinge has a high-temperature condensation origin (cf, MacPherson et al. 1988). However, later investigations suggested that Fremdlinge should have a high-temperature origin but have experienced aqueous alteration (including oxidation and sulfidization) to various degrees (Krot et al. 1995; Hsu et al. 2006). The aqueous alteration can also account for the presence of low-temperature mineral phases in Fremdlinge. In the present study, we also favor an aqueous alteration origin for the scheelite, molybdenite, and gypsum in some RMNs from CAI 007. The original refractory metal probably contains $\mathrm{Os}, \mathrm{Ir}, \mathrm{Ru}, \mathrm{Fe}, \mathrm{Ni}, \mathrm{W}$, and Mo. During aqueous alteration, the refractory metal reacted with fluids containing $\mathrm{Ca}, \mathrm{S}$, and $\mathrm{O}$. As a 
Table 2. EPMA compositions (wt\%) of davisite in CAI-007.

\begin{tabular}{|c|c|c|c|c|c|c|c|c|c|c|}
\hline & 14 & 15 & 16 & 17 & 18 & 20 & 26 & 28 & 29 & 30 \\
\hline $\mathrm{SiO}_{2}$ & 19.6 & 17.3 & 14.0 & 17.9 & 12.7 & 15.3 & 15.1 & 16.3 & 17.7 & 17.0 \\
\hline $\mathrm{TiO}_{2}{ }^{\text {tot }}$ & 8.2 & 8.7 & 6.0 & 7.0 & 6.2 & 7.5 & 7.5 & 6.3 & 7.7 & 7.0 \\
\hline $\mathrm{Ti}_{2} \mathrm{O}_{3}$ & 5.1 & 5.0 & 1.4 & 2.8 & 0.74 & 2.9 & 2.1 & 2.3 & 3.6 & 0.99 \\
\hline $\mathrm{TiO}_{2}$ & 2.5 & 3.1 & 4.4 & 3.9 & 5.3 & 4.3 & 5.2 & 3.8 & 3.6 & 5.9 \\
\hline $\mathrm{ZrO}_{2}$ & 8.5 & 10.4 & 14.0 & 9.0 & 14.6 & 12.5 & 10.2 & 12.8 & 10.5 & 11.0 \\
\hline $\mathrm{Al}_{2} \mathrm{O}_{3}$ & 25.1 & 27.1 & 28.0 & 26.5 & 28.0 & 27.9 & 26.9 & 27.2 & 26.6 & 26.4 \\
\hline $\mathrm{Cr}_{2} \mathrm{O}_{3}$ & bdl & 0.03 & 0.08 & bdl & 0.10 & 0.03 & 0.02 & bdl & bdl & 0.08 \\
\hline $\mathrm{Sc}_{2} \mathrm{O}_{3}$ & 14.4 & 13.3 & 15.4 & 14.5 & 14.7 & 14.0 & 15.7 & 12.8 & 13.4 & 13.7 \\
\hline $\mathrm{Y}_{2} \mathrm{O}_{3}$ & 0.33 & 0.68 & 0.55 & 0.22 & 0.61 & 0.58 & 0.38 & 0.32 & 0.34 & 0.39 \\
\hline $\mathrm{MgO}$ & 0.44 & 0.31 & 0.25 & 0.51 & 0.12 & 0.41 & 0.18 & 0.52 & 0.89 & 1.0 \\
\hline $\mathrm{FeO}$ & 0.42 & 0.23 & 0.35 & 0.09 & 0.49 & 0.20 & 0.07 & 0.25 & 0.30 & 1.8 \\
\hline $\mathrm{MnO}$ & 0.09 & 0.10 & 0.05 & 0.26 & bdl & bdl & 0.17 & bdl & 0.06 & bdl \\
\hline $\mathrm{CaO}$ & 22.8 & 22.3 & 21.8 & 22.5 & 21.7 & 22.1 & 21.9 & 22.8 & 22.1 & 21.7 \\
\hline $\mathrm{Na}_{2} \mathrm{O}$ & bdl & bdl & bdl & 0.02 & bdl & 0.05 & bdl & bdl & 0.04 & 0.13 \\
\hline $\mathrm{K}_{2} \mathrm{O}$ & bdl & bdl & bdl & bdl & bdl & bdl & 0.02 & 0.02 & bdl & bdl \\
\hline Total & 99.8 & 100.4 & 100.3 & 98.5 & 99.1 & 100.5 & 98.2 & 99.3 & 99.5 & 100.3 \\
\hline $\mathrm{Si}$ & 0.802 & 0.710 & 0.581 & 0.742 & 0.537 & 0.631 & 0.635 & 0.678 & 0.728 & 0.699 \\
\hline $\mathrm{Ti}^{3+}$ & 0.176 & 0.172 & 0.047 & 0.096 & 0.026 & 0.096 & 0.072 & 0.076 & 0.125 & 0.034 \\
\hline $\mathrm{Ti}^{4+}$ & 0.076 & 0.095 & 0.139 & 0.123 & 0.170 & 0.136 & 0.166 & 0.121 & 0.112 & 0.182 \\
\hline $\mathrm{Zr}$ & 0.170 & 0.208 & 0.284 & 0.181 & 0.303 & 0.252 & 0.208 & 0.260 & 0.211 & 0.221 \\
\hline $\mathrm{Al}$ & 1.210 & 1.311 & 1.371 & 1.288 & 1.394 & 1.354 & 1.329 & 1.335 & 1.290 & 1.273 \\
\hline $\mathrm{Cr}$ & bdl & 0.001 & 0.003 & bdl & 0.003 & 0.001 & 0.001 & bdl & bdl & 0.002 \\
\hline $\mathrm{Sc}$ & 0.512 & 0.475 & 0.558 & 0.521 & 0.543 & 0.502 & 0.574 & 0.465 & 0.479 & 0.488 \\
\hline $\mathrm{Y}$ & 0.007 & 0.015 & 0.012 & 0.005 & 0.014 & 0.013 & 0.008 & 0.007 & 0.007 & 0.008 \\
\hline $\mathrm{Mg}$ & 0.027 & 0.019 & 0.015 & 0.031 & 0.007 & 0.025 & 0.011 & 0.032 & 0.055 & 0.063 \\
\hline $\mathrm{Fe}$ & 0.014 & 0.008 & 0.012 & 0.003 & 0.017 & 0.007 & 0.003 & 0.009 & 0.010 & 0.062 \\
\hline $\mathrm{Mn}$ & 0.003 & 0.003 & 0.002 & 0.009 & bdl & bdl & 0.006 & bdl & 0.002 & bdl \\
\hline $\mathrm{Ca}$ & 1.003 & 0.982 & 0.975 & 0.998 & 0.984 & 0.979 & 0.987 & 1.016 & 0.977 & 0.956 \\
\hline $\mathrm{Na}$ & bdl & bdl & bdl & 0.002 & bdl & 0.004 & bdl & bdl & 0.003 & 0.01 \\
\hline $\mathrm{K}$ & bdl & bdl & bdl & bdl & bdl & bdl & 0.001 & 0.001 & bdl & bdl \\
\hline $\mathrm{Ti}^{3+} / \mathrm{Ti}^{\mathrm{tot}}$ & 0.7 & 0.65 & 0.25 & 0.44 & 0.13 & 0.41 & 0.3 & 0.39 & 0.53 & 0.16 \\
\hline
\end{tabular}

Cations are calculated based on six oxygen atoms.

bdl $=$ below detection limit.

consequence, scheelite, gypsum, troilite, and molybdenite formed together with osmium and hexaferrum.

Some mineralogical features in CAI 007 and the NWA 3118 chondrite might involve elemental diffusions and thermal metamorphism. These include $\mathrm{Fe}-\mathrm{Mg}$ interdiffusion in spinel and olivine and exsolution lamellae in a few refractory metal grains. It is widely accepted that primitive refractory inclusions were formed under reducing nebular conditions under which $\mathrm{Ti}^{3+}$ bearing silicate and oxide minerals are common observed (Grossman et al. [2008] and references therein; Ma and Rossman 2009a, 2009b; Zhang and Hsu 2009; Zhang and Yurimoto 2013; Zhang et al. 2015; Ma et al. 2017; Ma 2019). In the present study, the calculated $\mathrm{Ti}^{3+} / \mathrm{Ti}^{\text {tot }}$ values in davisite are consistent with those in Ti-rich diopside from other primitive CAIs (e.g., Simon and Grossman 2006; Simon et al. 2007, 2008, 2012; Zhang and Hsu 2009; Zhang and Yurimoto 2013; Zhang et al. 2015), indicating that CAI 007 should also have formed under reducing nebular condition. The presence of scheelite and molybdenite in some RMNs also supports this inference. Oxides of $\mathrm{W}$ and Mo are highly volatile in nebular settings (Fegley and Palme 1985). If the RMNs were formed under oxidizing nebular conditions, W and Mo would be oxidized and not form alloys with other refractory metal elements. Scheelite and molybdenite would not be observed in the refractory metal nuggets. This is in conflict with our observation. Given such a reducing condition, the Fe-rich feature of spinel and olivine in CAI 007 cannot be primordial and should be due to $\mathrm{Mg}-\mathrm{Fe}$ interdiffusion on the parent body. A similar $\mathrm{Mg}-\mathrm{Fe}$ interdiffusion process in NWA 3118 has been discussed in Matsuda et al. (2019). The calzirtite and tazheranite intergrowth might be another product of thermal metamorphism. Both calzirtite and tazheranite are $\mathrm{Zr}$,Sc-rich oxide phases, but have different structures (tetragonal and cubic, respectively) and compositions. Although they have similar $\mathrm{TiO}_{2}$ contents, calzirtite 
Table 3. EPMA compositions (wt\%) of spinel in CAI-007.

\begin{tabular}{|c|c|c|c|c|c|c|c|c|c|c|}
\hline & Spine & & & & Spine & & & Spinel & & \\
\hline & 23 & 27 & 28 & 31 & 31 & 32 & 35 & 4 & 16 & 25 \\
\hline $\mathrm{SiO}_{2}$ & 0.16 & 0.14 & 0.13 & 0.34 & 0.07 & 0.02 & 0.09 & 0.11 & 0.86 & 0.18 \\
\hline $\mathrm{TiO}_{2}$ & 0.11 & 0.30 & 0.12 & 0.09 & 0.07 & 0.19 & 0.03 & 0.35 & 0.31 & 0.16 \\
\hline $\mathrm{ZrO}_{2}$ & bdl & bdl & 0.04 & 0.04 & bdl & Bdl & 0.07 & bdl & 0.47 & 0.17 \\
\hline $\mathrm{Al}_{2} \mathrm{O}_{3}$ & 65.4 & 62.6 & 63.1 & 62.9 & 65.1 & 65.3 & 67.2 & 66.6 & 66.6 & 68.2 \\
\hline $\mathrm{Cr}_{2} \mathrm{O}_{3}$ & 0.03 & 0.12 & 0.04 & 0.09 & 0.11 & 0.18 & 0.05 & 0.09 & 0.30 & 0.24 \\
\hline $\mathrm{Sc}_{2} \mathrm{O}_{3}$ & 0.06 & 0.04 & 0.05 & 0.02 & 0.09 & 0.02 & bdl & 0.05 & 0.08 & 0.08 \\
\hline $\mathrm{Y}_{2} \mathrm{O}_{3}$ & bdl & bdl & 0.06 & bdl & bdl & bdl & 0.05 & bdl & 0.06 & bdl \\
\hline $\mathrm{MgO}$ & 13.1 & 8.1 & 9.4 & 9.71 & 16.9 & 18.3 & 17.8 & 20.5 & 18.6 & 21.4 \\
\hline $\mathrm{FeO}$ & 21.3 & 28.2 & 27.1 & 26.4 & 17.3 & 15.5 & 14.3 & 11.3 & 12.1 & 9.1 \\
\hline $\mathrm{MnO}$ & 0.05 & 0.05 & 0.05 & 0.17 & 0.09 & 0.03 & 0.14 & 0.05 & bdl & bdl \\
\hline $\mathrm{CaO}$ & 0.24 & 0.21 & 0.20 & 0.12 & 0.08 & 0.13 & 0.12 & 0.23 & 0.79 & 0.24 \\
\hline $\mathrm{Na}_{2} \mathrm{O}$ & 0.04 & bdl & 0.06 & 0.13 & bdl & 0.06 & bdl & bdl & 0.02 & bdl \\
\hline $\mathrm{K}_{2} \mathrm{O}$ & bdl & bdl & 0.03 & bdl & 0.04 & bdl & 0.03 & 0.04 & 0.02 & Bdl \\
\hline Total & 100.5 & 99.7 & 100.3 & 100.0 & 99.9 & 99.7 & 99.9 & 99.3 & 100.2 & 99.7 \\
\hline $\mathrm{Si}$ & 0.004 & 0.004 & 0.003 & 0.009 & 0.002 & 0.001 & 0.002 & 0.003 & 0.021 & 0.004 \\
\hline $\mathrm{Ti}$ & 0.002 & 0.006 & 0.002 & 0.002 & 0.001 & 0.004 & 0.001 & 0.007 & 0.006 & 0.003 \\
\hline $\mathrm{Zr}$ & bdl & bdl & 0.001 & 0.001 & bdl & bdl & 0.001 & bdl & 0.006 & 0.002 \\
\hline $\mathrm{Al}$ & 2.001 & 2.000 & 1.994 & 1.988 & 1.972 & 1.965 & 2.003 & 1.972 & 1.965 & 1.989 \\
\hline $\mathrm{Cr}$ & 0.001 & 0.003 & 0.001 & 0.002 & 0.002 & 0.004 & 0.001 & 0.002 & 0.006 & 0.005 \\
\hline $\mathrm{Sc}$ & 0.001 & 0.001 & 0.001 & 0.001 & 0.002 & 0.001 & bdl & 0.001 & 0.002 & 0.002 \\
\hline $\mathrm{Y}$ & bdl & bdl & 0.001 & bdl & bdl & bdl & 0.001 & bdl & 0.001 & bdl \\
\hline $\mathrm{Mg}$ & 0.512 & 0.328 & 0.377 & 0.391 & 0.653 & 0.701 & 0.677 & 0.774 & 0.699 & 0.795 \\
\hline $\mathrm{Fe}$ & 0.462 & 0.640 & 0.606 & 0.590 & 0.371 & 0.331 & 0.302 & 0.237 & 0.253 & 0.187 \\
\hline $\mathrm{Mn}$ & 0.001 & 0.001 & 0.001 & 0.004 & 0.002 & 0.001 & 0.003 & 0.001 & bdl & bdl \\
\hline $\mathrm{Ca}$ & 0.007 & 0.006 & 0.006 & 0.003 & 0.002 & 0.004 & 0.003 & 0.006 & 0.021 & 0.006 \\
\hline $\mathrm{Na}$ & 0.002 & bdl & 0.003 & 0.007 & bdl & 0.003 & bdl & bdl & 0.001 & bdl \\
\hline $\mathrm{K}$ & bdl & bdl & 0.001 & bdl & 0.001 & bdl & 0.001 & 0.001 & 0.001 & bdl \\
\hline Sum & 2.993 & 2.988 & 2.997 & 2.997 & 3.009 & 3.013 & 2.994 & 3.004 & 2.981 & 2.993 \\
\hline $\mathrm{Mg} \#$ & 0.53 & 0.34 & 0.38 & 0.40 & 0.64 & 0.68 & 0.69 & 0.77 & 0.73 & 0.81 \\
\hline
\end{tabular}

Cations are calculated based on four oxygen atoms.

bdl $=$ below detection limit.

${ }^{\mathrm{a}}$ Spinel in the core part.

${ }^{\mathrm{b}}$ Spinel intergrown with hibonite.

${ }^{\mathrm{c}}$ Spinel associated with Al-rich diopside in the rim.

contains much higher $\mathrm{ZrO}_{2}, \mathrm{Y}_{2} \mathrm{O}_{3}$, and $\mathrm{CaO}$ and lower $\mathrm{Sc}_{2} \mathrm{O}_{3}$ than tazheranite. They are probably decomposition products of a $\mathrm{Zr}$,Sc-rich oxide precursor during thermal metamorphism. Given that both aqueous alteration and thermal metamorphism are involved and heat-driving processes, they might have taken place in a common thermal event (fluid-assisted metamorphism).

\section{Condensation Origin of CAI 007 and Comparison with Other UR Inclusions}

The rare earth element pattern is an important criterion to constraining origin and formation process of refractory inclusions (Boynton 1975). Ultrarefractory inclusions are defined based on their uniquely UR REE pattern, complementary to Group II REE pattern. However, due to the rare presence of UR inclusions and the fine-grained feature of their constituent minerals, REE concentrations of UR inclusions and their constituent minerals were rarely measured (Palme et al. 1982; Simon et al. 1996; El Goresy et al. 2002; Ushikubo et al. 2004; Ma et al. 2013; Genzel et al. 2020). Our EPMA data show that the Y-rich perovskite contains high concentrations of the most refractory REEs (Gd, Tb, Dy, Ho, Er, and Lu), with other REEs having concentrations below the detection limit of EPMA. This result is well consistent with the UR REE pattern of other UR CAIs (e.g., Genzel et al. 2020; Fig. 11). Given the enrichments in $\mathrm{Zr}, \mathrm{Sc}, \mathrm{Ti}$, and the most refractory REEs, the CAI 007 should be a new UR inclusion, although, unfortunately, the REE concentrations in other minerals in CAI 007 cannot be determined using EPMA due to the high detection limit. 

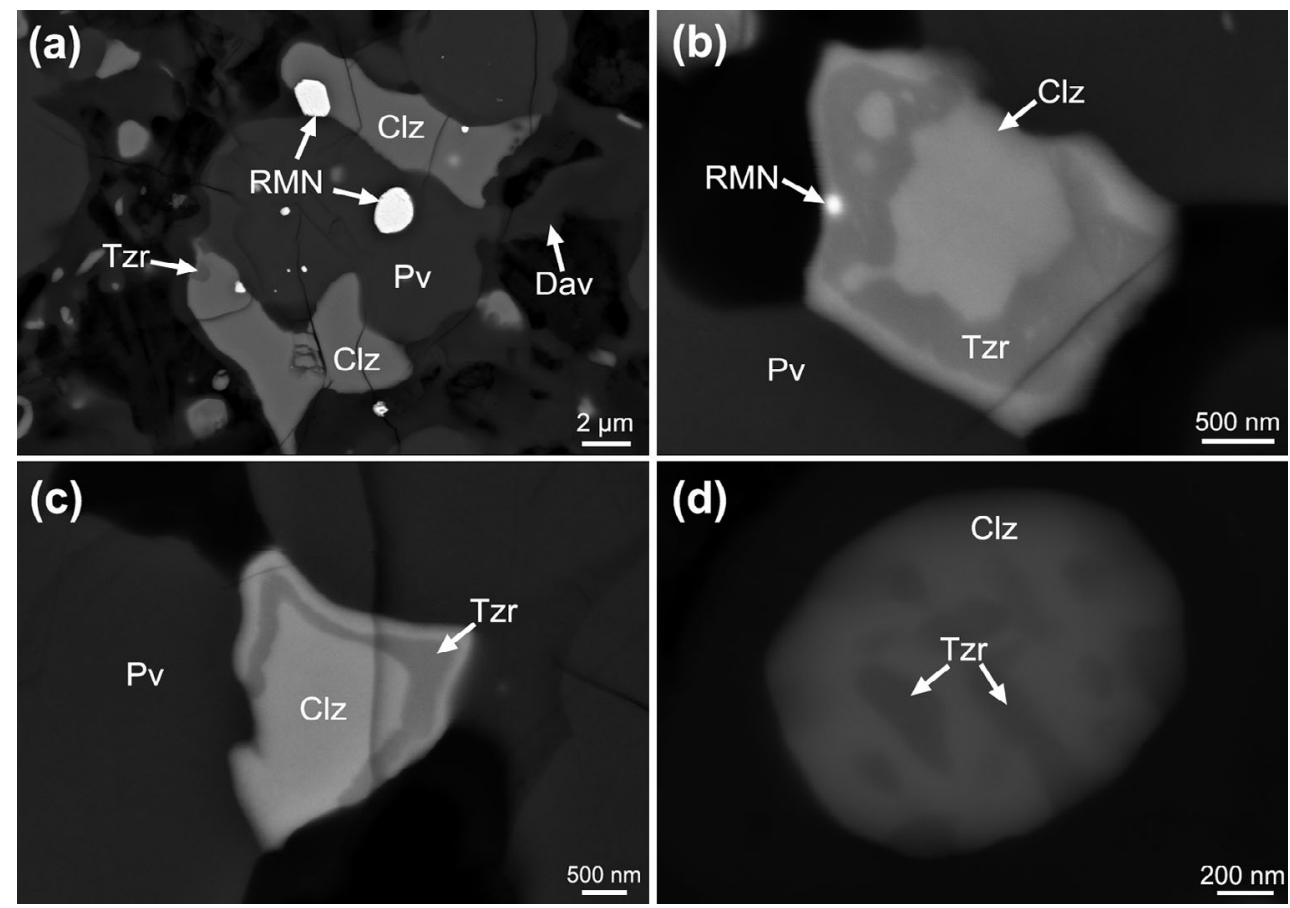

Fig. 5. BSE images of the $\mathrm{Zr}$,Sc-rich oxide minerals in the CAI 007. a) Calzirtite grains, which contain tiny grains of tazheranite, exist in the interstices of Y-rich perovskite. b-d) Complex petrographic textures between calzirtite and tazheranite. A tiny metal grain is also present as inclusion in tazheranite. $\mathrm{Pv}=$ perovskite; $\mathrm{Dav}=$ davisite; $\mathrm{Clz}=$ calzirtite; Tzr $=$ tazheranite; $\mathrm{RMN}=$ refractory metal nugget.
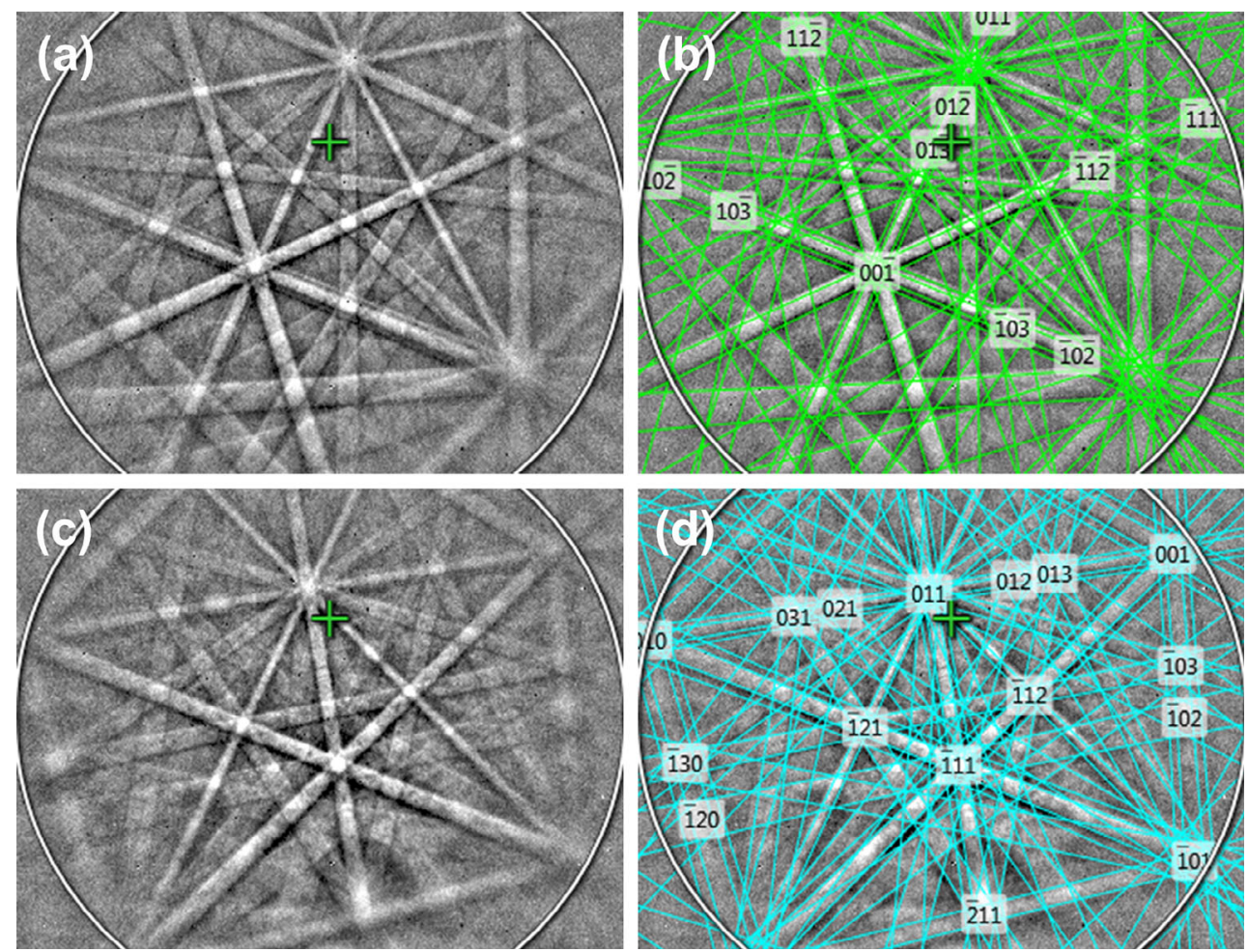

Fig. 6. EBSD patterns of calzirtite (a and b) and tazheranite (c and d) in CAI 007. a) EBSD pattern of calzirtite in CAI 007 and the pattern $\mathrm{b}$ ) indexed with the tetragonal $I_{1} /$ acd structure $(\mathrm{MAD}=0.29)$; c) EBSD pattern of tazheranite in CAI 007 and the pattern (d) indexed with the cubic Fm3m structure (MAD = 0.23). (Color figure can be viewed at wileyonlinelibrary.com.) 


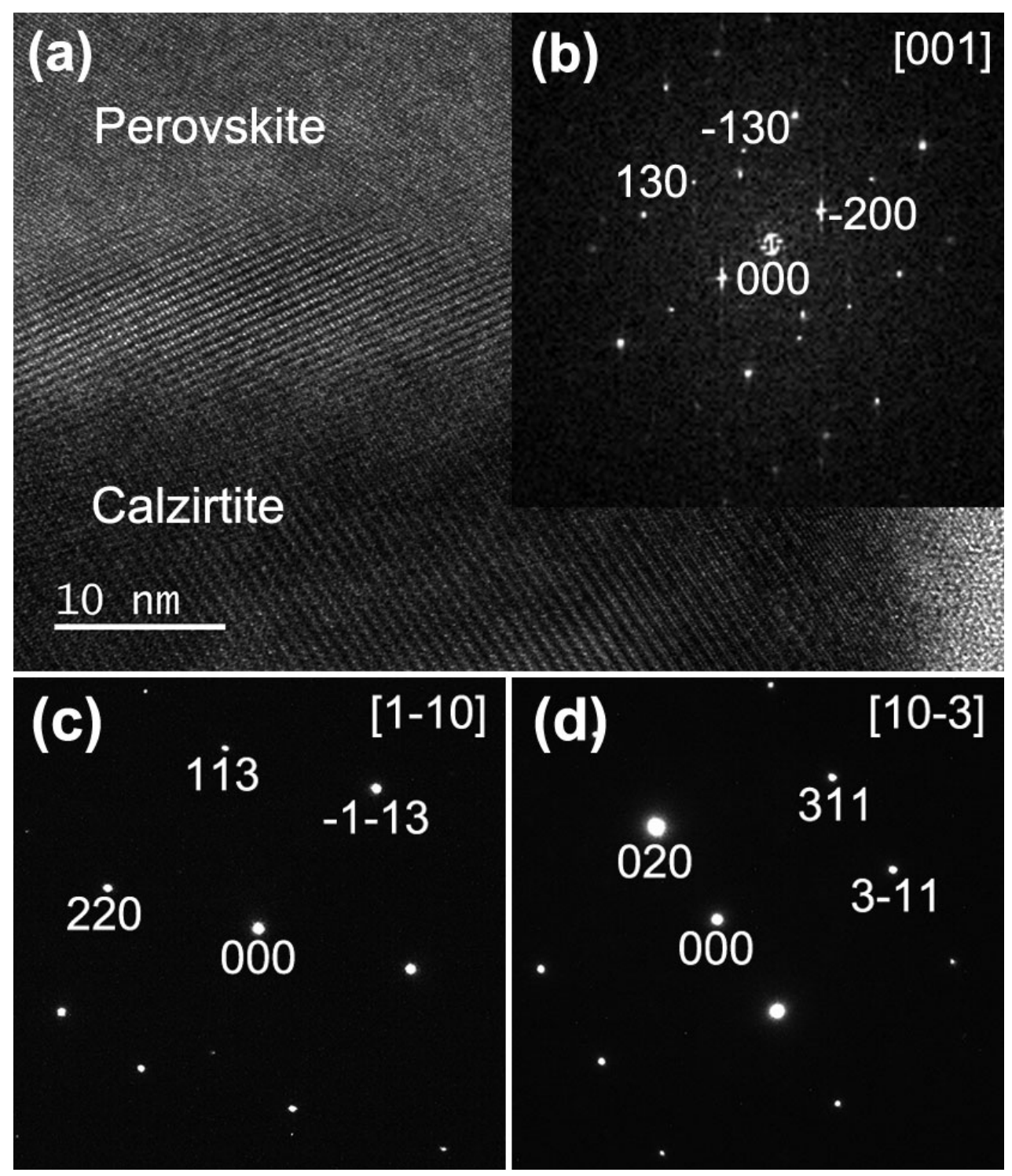

Fig. 7. High-resolution TEM image and selected area electron diffraction (SAED) patterns of the Zr,Sc-rich oxide minerals in CAI 007. a) High-resolution TEM image at the grain boundary between calzirtite and perovskite. b) Fast Fourier transfer image of the calzirtite grain shown in (a). c,d) SAED patterns of tazheranite.

Although CAI 007 has experienced fluid-assisted metamorphism on the parent body, its layered texture and the petrographic texture of the constituent minerals have been retained and can be used to constrain the formation sequence of the constituent minerals in this ultrarefractory inclusion. Given the layered texture and the porous texture of CAI 007, this UR inclusion should not have experienced melting and recrystallization. Instead, it might be of condensation or evaporative residue origin.

In CAI 007, the core is composed of RMNs, Y-rich perovskite, and $\mathrm{Zr}$,Sc-rich oxide and silicate minerals. If considering the $50 \%$ condensation temperatures of Ir,
Os, Ru, Y, Zr, and Sc (Lodders 2003), the formation temperature of the core might be approximately 1800 $1700 \mathrm{~K}$ (Komatsu et al. 2018). The hibonite-spinel intergrowth probably has formed at 1668-1628 K (Han et al. [2015] and references therein). The spinel-Aldiopside rim is much less refractory, probably forming at a temperature approximately 1400-1350 K (Komatsu et al. 2018). Such a relationship between condensation temperature and the layered texture can be interpreted in two ways. One is the whole CAI 007 is a condensation product from the solar nebular gas with three stages. In the first stage, RMNs crystallized as the first condensation phase from the nebular gas. 
Table 4. Chemical compositions of calzirtite and tazheranite in CAI-007.

\begin{tabular}{|c|c|c|c|c|c|c|c|c|}
\hline & \multicolumn{4}{|c|}{ Calzirtite-EPMA } & \multicolumn{4}{|c|}{ Tazheranite-TEM-EDS } \\
\hline & 21 & 22 & 25 & Average & 6 & 16 & 19 & Average \\
\hline$\overline{\mathrm{SiO}_{2}}$ & 0.04 & 0.19 & 0.11 & 0.11 & & & & \\
\hline $\mathrm{TiO}_{2}$ & 7.0 & 8.6 & 7.5 & 7.7 & 7.4 & 7.9 & 6.9 & 7.4 \\
\hline $\mathrm{ZrO}_{2}$ & 70.7 & 69.2 & 70.2 & 70.0 & 57.1 & 57.2 & 59.4 & 57.9 \\
\hline $\mathrm{Al}_{2} \mathrm{O}_{3}$ & 0.41 & 0.46 & 0.39 & 0.42 & & & & \\
\hline $\mathrm{Sc}_{2} \mathrm{O}_{3}$ & 13.0 & 12.0 & 13.0 & 12.6 & 33.8 & 32.6 & 31.2 & 32.5 \\
\hline $\mathrm{Y}_{2} \mathrm{O}_{3}$ & 3.2 & 3.7 & 3.5 & 3.5 & 0.74 & 0.90 & 0.86 & 0.83 \\
\hline $\mathrm{MgO}$ & 0.18 & 0.25 & 0.17 & 0.20 & & & & \\
\hline $\mathrm{FeO}$ & 0.26 & 0.39 & 0.07 & 0.24 & & & & \\
\hline $\mathrm{CaO}$ & 4.1 & 4.1 & 4.0 & 4.1 & 1.1 & 1.4 & 1.7 & 1.4 \\
\hline Total & 98.8 & 98.9 & 98.9 & 98.8 & 100 & 100 & 100 & 100 \\
\hline $\mathrm{Si}$ & 0.007 & 0.030 & 0.016 & 0.018 & & & & \\
\hline $\mathrm{Ti}^{\mathrm{tot}}$ & 0.813 & 0.985 & 0.869 & 0.889 & 0.086 & 0.092 & 0.082 & 0.087 \\
\hline $\mathrm{Ti}^{4+}$ & 0.403 & 0.557 & 0.398 & 0.453 & & & & \\
\hline $\mathrm{Ti}^{3+}$ & 0.410 & 0.428 & 0.471 & 0.436 & & & & \\
\hline $\mathrm{Zr}$ & 5.343 & 5.202 & 5.299 & 5.281 & 0.434 & 0.436 & 0.456 & 0.442 \\
\hline $\mathrm{Al}$ & 0.075 & 0.083 & 0.071 & 0.076 & & & & \\
\hline $\mathrm{Sc}$ & 1.748 & 1.605 & 1.748 & 1.700 & 0.458 & 0.443 & 0.427 & 0.443 \\
\hline $\mathrm{Y}$ & 0.262 & 0.305 & 0.284 & 0.284 & 0.003 & 0.004 & 0.004 & 0.003 \\
\hline $\mathrm{Mg}$ & 0.043 & 0.058 & 0.040 & 0.047 & & & & \\
\hline $\mathrm{Fe}$ & 0.034 & 0.049 & 0.009 & 0.031 & & & & \\
\hline $\mathrm{Ca}$ & 0.676 & 0.682 & 0.664 & 0.674 & 0.018 & 0.024 & 0.029 & 0.023 \\
\hline Sum & 9.000 & 9.000 & 9.000 & 9.000 & 0.999 & 0.999 & 0.997 & 0.998 \\
\hline
\end{tabular}

Cations of calzirtite are calculated based on 16 oxygen atoms. The concentrations of $\mathrm{Ti}^{3+}$ are calculated based on the ideal stoichiometry of calzirtite ( 9 cations per 16 oxygen atoms).

Cations of tazheranite are calculated based on 1.75 oxygen atoms.

Subsequently, Y-rich perovskite and $\mathrm{Zr}$,Sc-rich oxides (their precursor) condensed and the former phase might be earlier, given that most $\mathrm{Zr}$,Sc-rich oxide phases occur at the interstices of Y-rich perovskite. Then, fine-grained davisite and minor spinel condensed and surrounded early-formed RMNs, Y-rich perovskite, and $\mathrm{Zr}$,Sc-rich oxide phases. It is also possible that davisite might have formed through a reaction between $\mathrm{Zr}$,Sc-rich oxide(s) and $\mathrm{SiO}$, Cabearing nebular gas ( $\mathrm{Ma}$ et al. 2020). In the second stage, spinel and hibonite condensed together on the ultrarefractory core part. In the third stage, spinel and Al-rich diopside condensed and formed the rim. The other possibility is that the core is an evaporative residue whereas the other two parts are condensates after the formation of the $\mathrm{Zr}, \mathrm{Sc}, \mathrm{Y}$-rich core. If assuming that $\mathrm{Zr}$,Sc-rich oxide phases form at a higher temperature than $\mathrm{Zr}$,Sc-rich silicate phase (davisite), the petrographic texture of the core may be indicative of condensation rather than evaporation residue. Generally, we prefer a condensation origin of CAI 007 based on its petrography and mineralogy.

Recently, Krot et al. (2019a) compared mineral assemblages of known ultrarefractory inclusions including the $3 N-24$ UR CAI from NWA 3118. Based on their comparison, refractory metal nuggets, perovskite, davisite, spinel, and Al-rich diopside are the most common minerals in ultrarefractory inclusions, with warkite, hibonite, and melilite relatively less common (Krot et al. 2019a; Ma et al. 2020). From this aspect, the mineral assemblage of CAI 007 is similar to most ultrarefractory inclusions, although no warkite and melilite were observed in CAI 007.

The UR CAI $3 N-24$ in NWA 3118 has been studied by previous investigators (Ivanova et al. 2012, 2015; Krot et al. 2019a; Genzel et al. 2020). It contains Y-rich perovskite, two $\mathrm{Zr}$,Sc-rich oxide phases, Sc,Zr-rich pyroxene, and Al-rich pyroxene. Although both $3 N-24$ and CAI 007 are observed in the NWA 3118 chondrite, they are different in many aspects. The $3 N-24$ is an inclusion in a complex refractory inclusion; however, CAI 007 is an individual inclusion enclosed in the finegrained matrix. In mineralogy, the spinel-hibonite intergrowth was not observed in $3 N-24$ (Ivanova et al. 2012, 2015; Krot et al. 2019a), but is present in CAI 007. The davisite in CAI 007 also contains much higher $\mathrm{Sc}_{2} \mathrm{O}_{3}(12.8-15.7 \mathrm{wt} \%)$ than the $\mathrm{Zr}$,Sc-rich pyroxene $(<3.1 \mathrm{wt} \%)$ that directly surrounds $\mathrm{Zr}$,Sc-rich oxides (Ivanova et al. 2012). Ivanova et al. (2012) suggested that $3 N-24$ has experienced partial melting; however, 

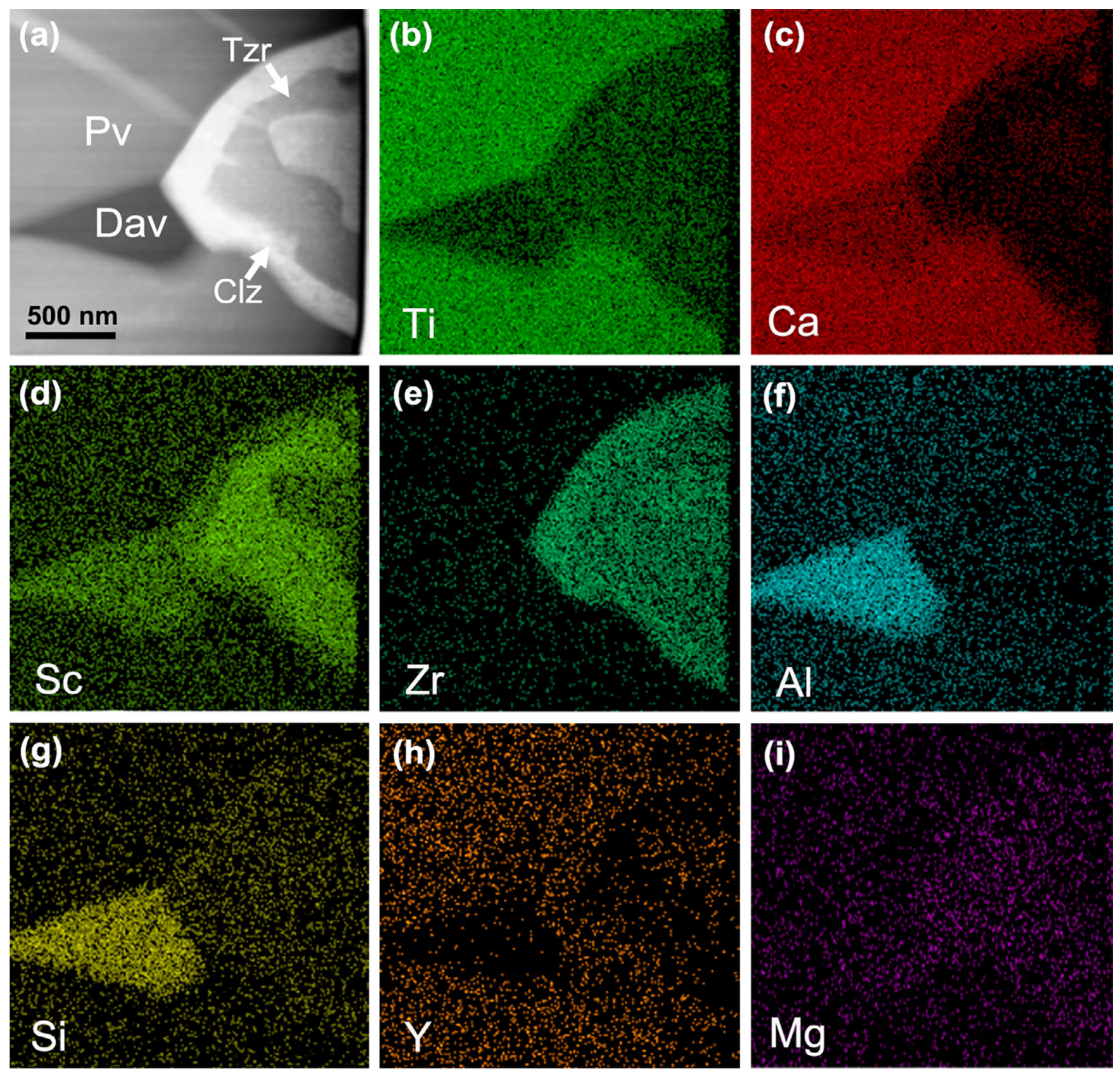

Fig. 8. a) HAADF-STEM image showing the complex texture between tazheranite and calzirtite in CAI 007 . b-i) X-ray elemental mapping results. Note that calzirtite contains higher $\mathrm{Ca}$ and $\mathrm{Y}$ concentrations than tazheranite. $\mathrm{Clz}=$ calzirtite; Dav = davisite; $\mathrm{Pv}=$ perovskite; $\mathrm{Tzr}=$ tazheranite. (Color figure can be viewed at wileyonlinelibrary.com.)

CAI 007 has not experienced subsequent hightemperature melting after its formation. Whether the above differences are due to different formation processes remains unclear. It is very likely that the two UR inclusions originally have different chemistry.

Zirconium, scandium-rich oxide phases are important UR minerals in CAI 007 and have also been observed in many of the other ultrarefractory inclusions (Ivanova et al. 2012; Rubin and Ma 2017; Krot et al. [2019a] and references therein; Ma et al. 2014, 2020). Ivanova et al. (2012) have compared the compositions of $\mathrm{Zr}$,Sc-rich oxide phases in the UR inclusions at that time. Figure 14 shows a comparison including the data for $\mathrm{Zr}$,Sc-rich oxide phases in CAI 007. The data show a large chemical variation in $\mathrm{ZrO}_{2}, \mathrm{Sc}_{2} \mathrm{O}_{3}, \mathrm{TiO}_{2}, \mathrm{Y}_{2} \mathrm{O}_{3}$, and $\mathrm{CaO}$ (Fig. 14). However, unfortunately, structural information is usually absent for most of these $\mathrm{Zr}$,Scrich oxide phases. We will first compare these data from 

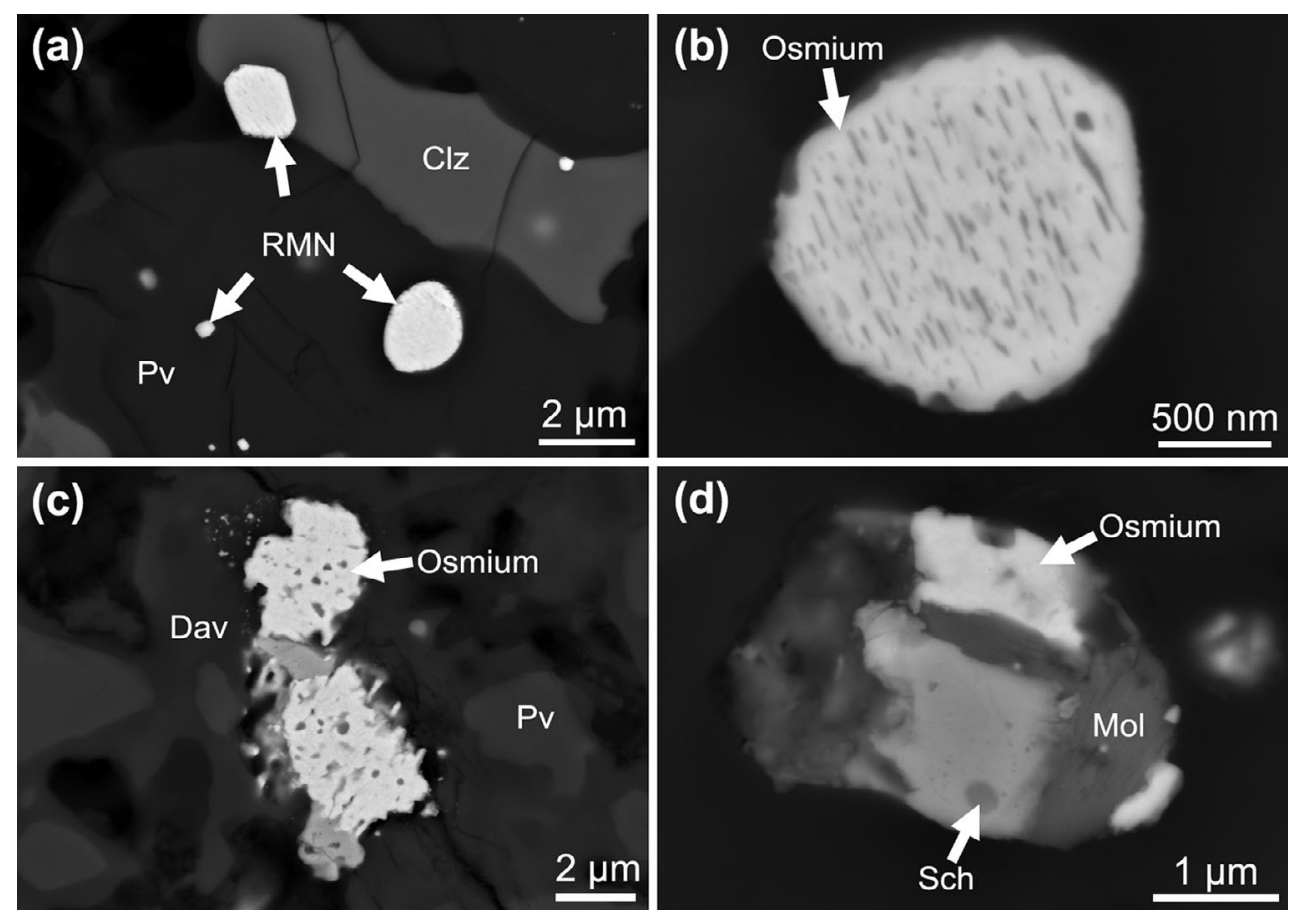

Fig. 9. BSE images showing refractory metal nuggets in CAI 007. a) Some refractory metal grains are totally enclosed by perovskite while one grain is partly included in calzirtite. b) One refractory metal grain (Os,Ir-alloy) contains very fine exsolution lamellae (Fe,Fe-alloy). c,d) Refractory metal grains are associated with other mineral phases like scheelite and molybdenite. $\mathrm{RMN}=$ refractory metal nugget; $\mathrm{Pv}=$ perovskite; $\mathrm{Clz}=$ calzirtite; Dav $=$ davisite; Mol = molybdenite; Sch = scheelite.

those phases with structural information (Ma and Rossman 2008; Ma et al. 2014).

Ma and Rossman (2008) reported the presence of Y-rich tazheranite in Allende with both structural and chemical information. Ma et al. (2014) reported the coexistence of two $\mathrm{Zr}$,Sc-rich oxide phases (allendeite and tazheranite) within an UR inclusion from Allende. Allendeite and tazheranite belong to trigonal and cubic crystal systems, respectively. Both allendeite and tazheranite reported in Ma et al. (2014) have a welldefined chemical formula. According to the plot in Fig. 14, the Zr,Sc-rich oxide in Acfer 182 and the darker $\mathrm{Zr}$,Sc-rich oxide phase in CAI 007 have chemical compositions similar to allendeite. They are the most Sc-rich phase(s) in the currently known refractory inclusions. However, interestingly, the darker $\mathrm{Zr}$,Sc-rich oxide phase in CAI 007 is chemically $\left(\mathrm{MO}_{1.75}, \mathrm{M}=\mathrm{Zr}\right.$, $\mathrm{Sc}, \mathrm{Ca}, \mathrm{Ti}$, and $\mathrm{Y}$ ) and structurally consistent with tazheranite rather than allendeite. The reason for this discrepancy is unclear. It might be due to their various formation processes and/or subtle chemical difference. In chemistry, allendeite contains $\mathrm{CaO}$ higher than those in the tazheranite in CAI 007 and the $\mathrm{Zr}$,Sc-rich oxide in Acfer-182. However, the tazheranite in CAI 007 has a composition distinctly different from that in Allende and the tazheranite in other meteorites ( $\mathrm{Ma}$ and
Rossman 2008; Ivanova et al. 2012; Ma et al. 2014; Fig. 14). If all these are indeed tazheranite, tazheranite in nature might form a rather wide solid solution with other phases.

Calzirtite in CAI 007 has $\mathrm{ZrO}_{2}, \mathrm{TiO}_{2}$, and $\mathrm{CaO}$ contents similar to the $\mathrm{Zr}$,Sc-rich oxide- 1 in the $3 N-24$ inclusion reported by Ivanova et al. (2012) and the Zr, Sc-rich oxide phase in Orans reported by Noonan et al. (1977). However, they have different $\mathrm{Y}_{2} \mathrm{O}_{3}$ and $\mathrm{Sc}_{2} \mathrm{O}_{3}$ contents. Recently, Ma (2020) reported the presence of calzirtite in the Leoville $\mathrm{CV} 3$ chondrite, which contains much lower $\mathrm{Sc}_{2} \mathrm{O}_{3}$ and higher $\mathrm{CaO}, \mathrm{TiO}_{2}$, and $\mathrm{Y}_{2} \mathrm{O}_{3}$ than other occurrence of calzirtite. Since their $\mathrm{ZrO}_{2}$ contents are generally constant, the compositional variation could be attributed to the cation substitution $\mathrm{Sc}^{3+} \mathrm{Y}^{3+}$ and $\mathrm{Ca}^{2+}+\mathrm{Ti}^{4+} 2 \mathrm{M}^{3+}$. Ivanova et al. (2012) also reported another $\mathrm{Zr}$,Sc-rich oxide phase besides tazheranite in the $33 E-1$ inclusion from the Efremovka CV3 chondrite. Its chemical composition plots in the region between calzirtite, tazheranite, and allendeite. If all the titanium in this phase is $\mathrm{Ti}^{4+}$, it requires a complex chemical formula to interpret its composition (Ivanova et al. 2012). This phase deserves further detailed observations to determine its texture with other $\mathrm{Zr}$,Sc-rich oxide phases, crystal structure, and valence states of titanium. 


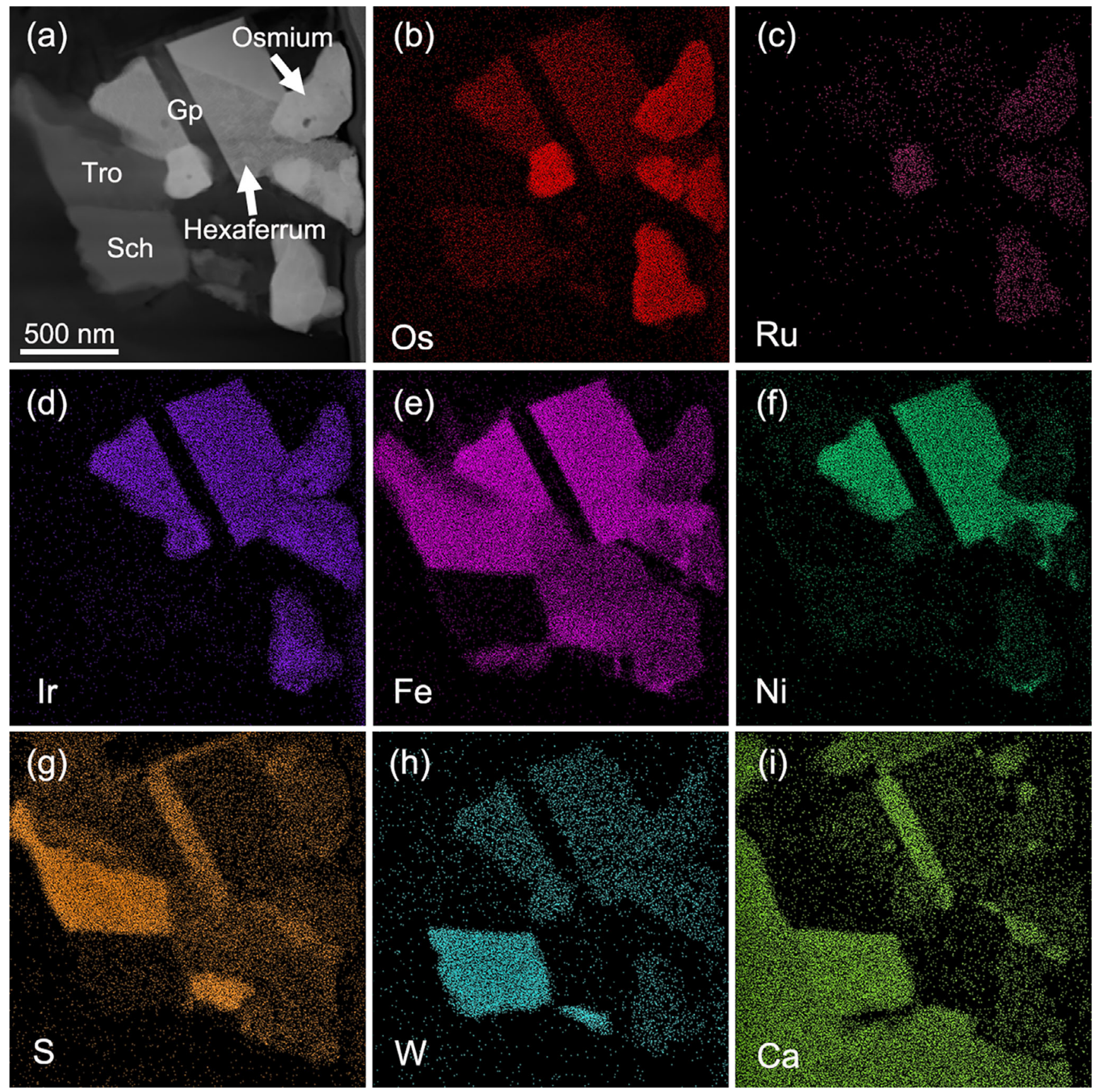

Fig. 10. a) HAADF-STEM image showing the mineral assemblage of a refractory metal nugget. b-i) X-ray elemental mapping results. $\mathrm{Gp}=$ gypsum; Hexaferrum = Fe,Ni-alloy; Osmium = Os,Ir-alloy; $\mathrm{Sch}=$ scheelite; Tro = troilite. (Color figure can be viewed at wileyonlinelibrary.com.)

\section{Oxygen Isotopic Heterogeneity in CAI 007}

Oxygen isotopic composition is an important factor of constraining the formation process, nebular condition, and post-formation history of CAIs in chondrites. Based on the models about the oxygen isotope distribution and evolution in the solar system
(Clayton 2002, 2003; Yurimoto and Kuramoto 2004; Lyons and Young 2005; Sakamoto et al. 2007), the solar nebular gas had a ${ }^{16} \mathrm{O}$-rich oxygen isotope composition, probably similar to that of the present solar wind (McKeegan et al. 2011). Most pristine CAIs in most unmetamorphosed carbonaceous chondrites are usually uniformly ${ }^{16} \mathrm{O}$-rich $\left(\Delta^{17} \mathrm{O} \sim-22 \%\right.$; Yurimoto 
Table 5. TEM-EDS compositions of osmium and hexaferrum in CAI-007.

\begin{tabular}{|c|c|c|c|c|c|c|c|c|c|c|c|}
\hline & \multicolumn{7}{|c|}{ Osmium } & \multicolumn{4}{|c|}{ Hexaferrum } \\
\hline & 4 & 7 & 8 & 9 & 17 & 22 & 24 & 6 & 16 & 23 & 30 \\
\hline $\mathrm{Fe}$ & 5.7 & 7.1 & 5.8 & 6.0 & 5.8 & 5.5 & 6.4 & 30.8 & 29.9 & 31.1 & 25.7 \\
\hline Mo & 0.69 & bdl & 1.6 & 0.66 & 0.87 & 1.2 & 2.1 & bdl & bdl & bdl & bdl \\
\hline $\mathrm{Ru}$ & 11.5 & 12.6 & 10.0 & 9.8 & 11.9 & 10.8 & 14.5 & 2.2 & bdl & bdl & 4.9 \\
\hline $\mathrm{Re}$ & 4.2 & 4.8 & 4.4 & 2.9 & 3.8 & 4.5 & 3.4 & bdl & bdl & bdl & bdl \\
\hline Total & 100.0 & 100.1 & 100.1 & 100.0 & 100.1 & 100.0 & 100.1 & 100.0 & 100.0 & 100.0 & 100.1 \\
\hline $\mathrm{Fe}$ & 15.48 & 18.69 & 15.87 & 16.35 & 15.69 & 15.10 & 16.70 & 48.44 & 48.60 & 49.56 & 44.42 \\
\hline $\mathrm{Ni}$ & 1.05 & 1.12 & 1.15 & 1.22 & 1.02 & 1.27 & 1.14 & 27.27 & 26.31 & 26.66 & 22.89 \\
\hline Mo & 1.10 & bdl & 2.51 & 1.05 & 1.36 & 1.93 & 3.16 & bdl & bdl & bdl & bdl \\
\hline $\mathrm{Ru}$ & 17.3 & 18.37 & 15.03 & 14.81 & 17.72 & 16.26 & 20.84 & 1.93 & bdl & bdl & 4.66 \\
\hline
\end{tabular}

Metal atoms are calculated based on 100 atoms.

bdl $=$ below detection limit.

Table 6. EPMA compositions ( $\mathrm{wt} \%$ ) of hibonite and Al-rich diopside in CAI-007.

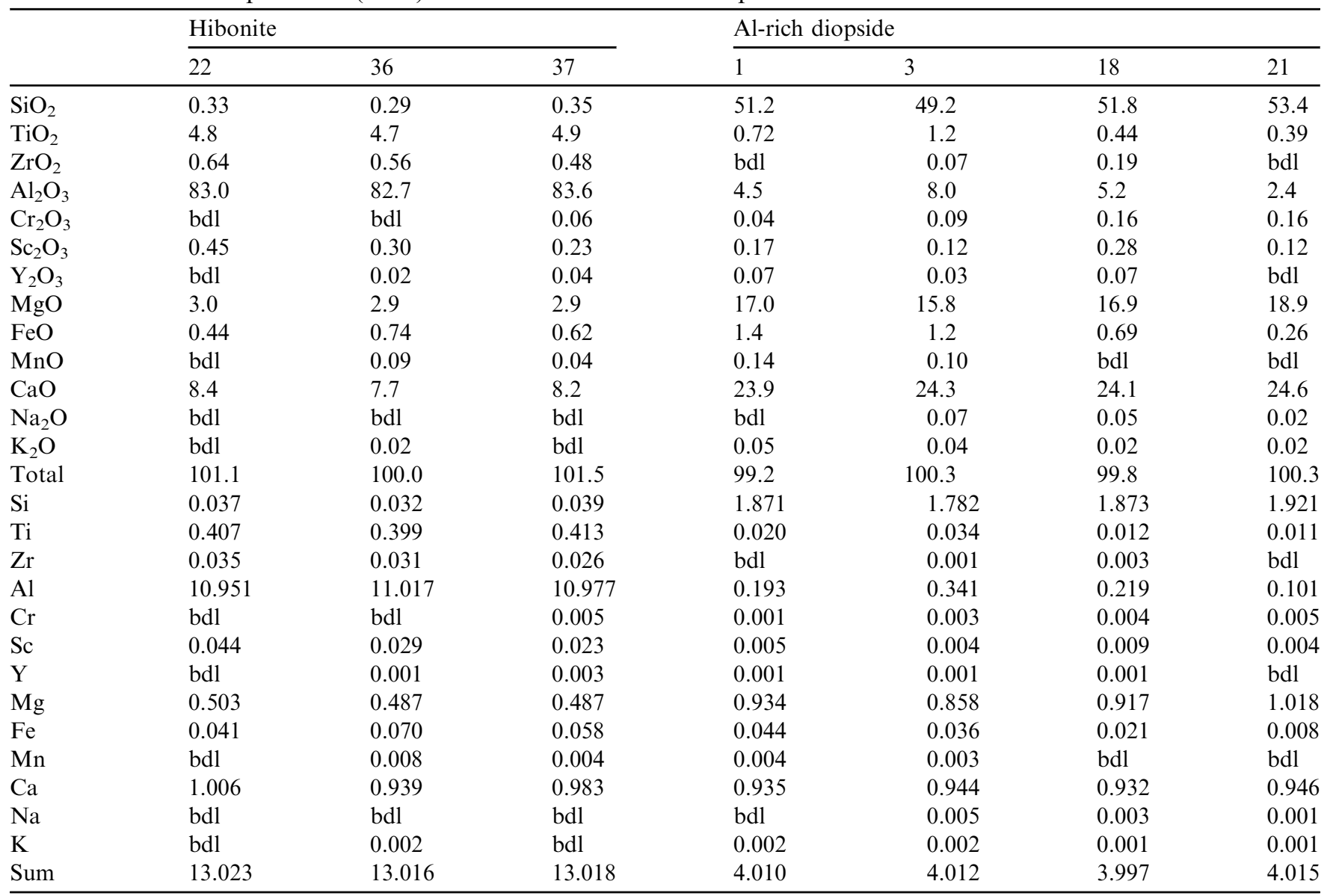

Cations of hibonite are calculated based on 19 oxygen atoms.

Cations of Al-rich diopside are calculated based on six oxygen atoms.

bdl $=$ below detection limit. 


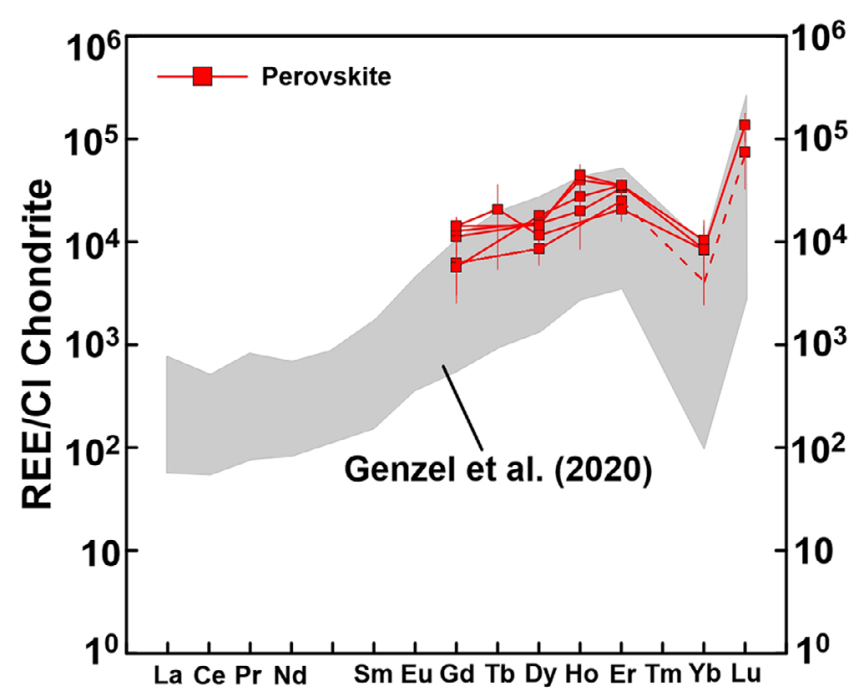

Fig. 11. Rare earth element compositions of perovskite in CAI 007. The shaded area shows the REE compositions of minerals in other UR CAIs reported in Genzel et al. (2020). The local dashed line indicates the concentration of $\mathrm{Yb}$ is below detection limit of EPMA analysis and the pattern is arbitrarily drawn. (Color figure can be viewed at wileyonline library.com.) et al. 2008; Krot et al. 2012) and should have formed in the ${ }^{16}$ O-rich gaseous reservoirs (Yurimoto et al. 2008). Meanwhile, numerous investigations suggested that ${ }^{16} \mathrm{O}$ poor gaseous reservoirs might also exist in the CAI formation regions (Yurimoto et al. 1998; Simon et al. 2011; Katayama et al. 2012; Kawasaki et al. 2012, 2017; Park et al. 2012; Zhang et al. 2015; Yoshizaki et al. 2019; Krot et al. 2019a, 2019b). The presence of ${ }^{16} \mathrm{O}$ poor gaseous reservoirs might have led to the formation of uniformly ${ }^{16} \mathrm{O}$-poor CAIs and CAIs with heterogeneous oxygen isotopic compositions. It is also argued that post-crystallization oxygen isotope exchange might account for the ${ }^{16} \mathrm{O}$-poor feature of some CAIs (Wasson et al. 2001; Kawasaki et al. 2015, 2018; Simon et al. 2019; Krot et al. 2019a, 2019b).

Recently, Krot et al. (2019a) reported high quality SIMS oxygen isotopic compositions for minerals in 25 UR inclusions, and interpreted these oxygen isotopic compositions by all of the above situations. The CAI 007 UR inclusion in this study also shows a large variation among different minerals, with spinel and hibonite being ${ }^{16} \mathrm{O}$-rich, perovskite and davisite being

Table 7. Oxygen isotope compositions $(\%)$ of minerals in CAI-007.

\begin{tabular}{|c|c|c|c|c|c|c|}
\hline Spot\# & $\delta^{18} \mathrm{O}$ & $2 \sigma$ & $\delta^{17} \mathrm{O}$ & $2 \sigma$ & $\Delta^{17} \mathrm{O}$ & $2 \sigma$ \\
\hline \multicolumn{7}{|c|}{$\mathrm{Zr}, \mathrm{Sc}, \mathrm{Y}$-rich core } \\
\hline \multicolumn{7}{|c|}{ Perovskite } \\
\hline @331 & 4.9 & 0.7 & 0.6 & 1.7 & -1.9 & 1.7 \\
\hline @ 362 & 6.0 & 0.9 & -0.6 & 2.0 & -3.7 & 2.0 \\
\hline @ 363 & 6.4 & 0.9 & -0.5 & 2.1 & -3.8 & 2.2 \\
\hline \multicolumn{7}{|l|}{ Davisite } \\
\hline @ 332 & 10.4 & 1.1 & 4.1 & 2.5 & -1.3 & 2.5 \\
\hline @ 361 & 10.2 & 1.4 & 0.0 & 2.8 & -5.3 & 2.9 \\
\hline \multicolumn{7}{|l|}{ Spinel } \\
\hline @ 394 & -39.5 & 1.2 & -44.8 & 2.0 & -24.3 & 2.1 \\
\hline \multicolumn{7}{|c|}{ Hibonite-spinel intergrowth } \\
\hline \multicolumn{7}{|c|}{ Hibonite } \\
\hline$@ 360$ & -37.7 & 1.5 & -42.1 & 3.4 & -22.5 & 3.5 \\
\hline \multicolumn{7}{|l|}{ Spinel } \\
\hline @ 357 & -36.7 & 1.3 & -41.5 & 2.8 & -22.4 & 2.9 \\
\hline @358 & -38.6 & 1.4 & -41.8 & 2.8 & -21.7 & 2.9 \\
\hline @ 359 & -38.3 & 1.2 & -42.7 & 2.7 & -22.8 & 2.8 \\
\hline \multicolumn{7}{|c|}{ Spinel-diopside rim } \\
\hline \multicolumn{7}{|l|}{ Spinel } \\
\hline @365 & -37.2 & 1.2 & -41.5 & 2.7 & -22.2 & 2.8 \\
\hline \multicolumn{7}{|c|}{ Al-rich diopside } \\
\hline @364 & -25.8 & 1.5 & -33.7 & 3.1 & -20.3 & 3.2 \\
\hline @366 & -24.7 & 1.7 & -29.8 & 3.6 & -17.0 & 3.7 \\
\hline @367 & -16.3 & 1.6 & -20.6 & 3.4 & -12.1 & 3.5 \\
\hline
\end{tabular}




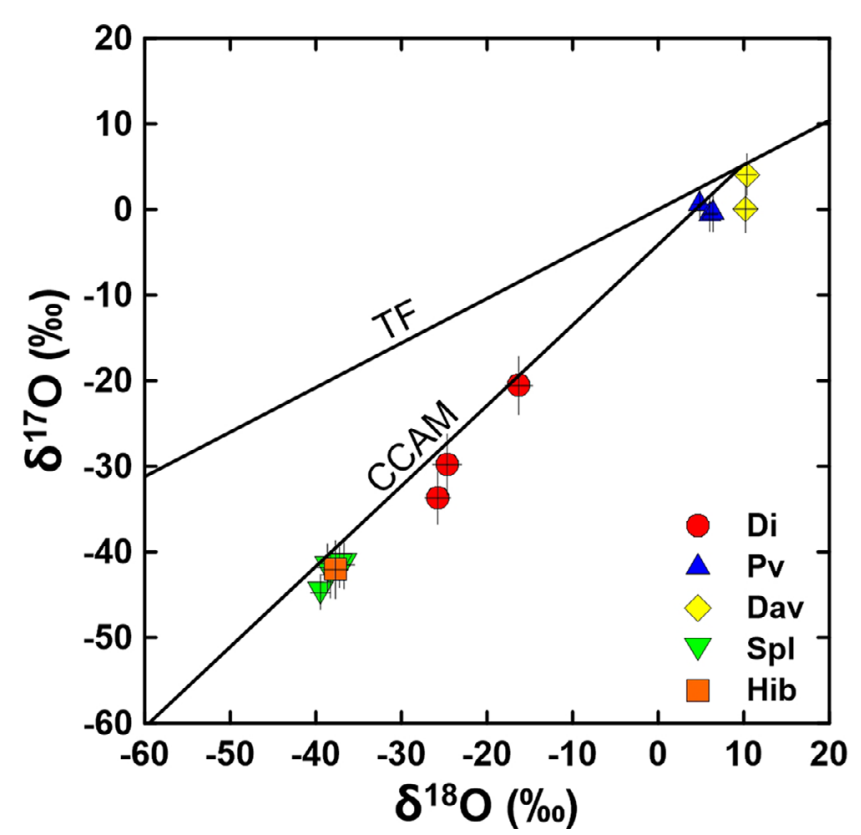

Fig. 12. Oxygen isotope compositions of minerals in CAI 007. The terrestrial fractionation (TF) line and carbonaceous chondrite anhydrous mineral (CCAM) line are adopted from Clayton et al. (1977). Error bars are 2 $\sigma$. (Color figure can be viewed at wileyonlinelibrary.com.)

${ }^{16} \mathrm{O}$-poor, and Al-rich diopside being intermediately ${ }^{16} \mathrm{O}$-rich in oxygen isotopic composition.

Wasson et al. (2001) demonstrated that oxygen isotope compositions of fine-grained minerals (normally less than $10 \mu \mathrm{m}$ ) changed toward the ${ }^{16} \mathrm{O}$-poor direction by aqueous alteration on the parent body because the aqueous fluids were ${ }^{16} \mathrm{O}$-poor. Krot et al. (2019a) also suggested that some minerals in the UR inclusions might have experienced oxygen isotope exchange with aqueous fluids on the chondrite parent bodies. The isotope exchange might be controlled by combination of diffusion, dissolution, and grain growth mechanisms (Nakamura et al. 2005). Such a scenario can also account for the oxygen isotope distribution among different minerals in CAI 007, given that CAI 007 has experienced fluid-assisted metamorphism as discussed in the previous section.

The minerals show a large variation of oxygen isotopic composition among different minerals in CAI 007. All the measured spinel grains are as ${ }^{16} \mathrm{O}$-enriched as those of the most primitive UR CAIs. The ${ }^{16} \mathrm{O}$-rich oxygen isotopic feature of spinel and hibonite indicates that they were formed in the ${ }^{16} \mathrm{O}$-rich nebular setting. Davisite and perovskite are ${ }^{16} \mathrm{O}$-poor, suggesting that these minerals were probably formed in the ${ }^{16} \mathrm{O}$-poor nebular setting or their oxygen isotopic signature might have been reset on the parent body because the oxygen diffusion coefficient of perovskite is large (Sakaguchi

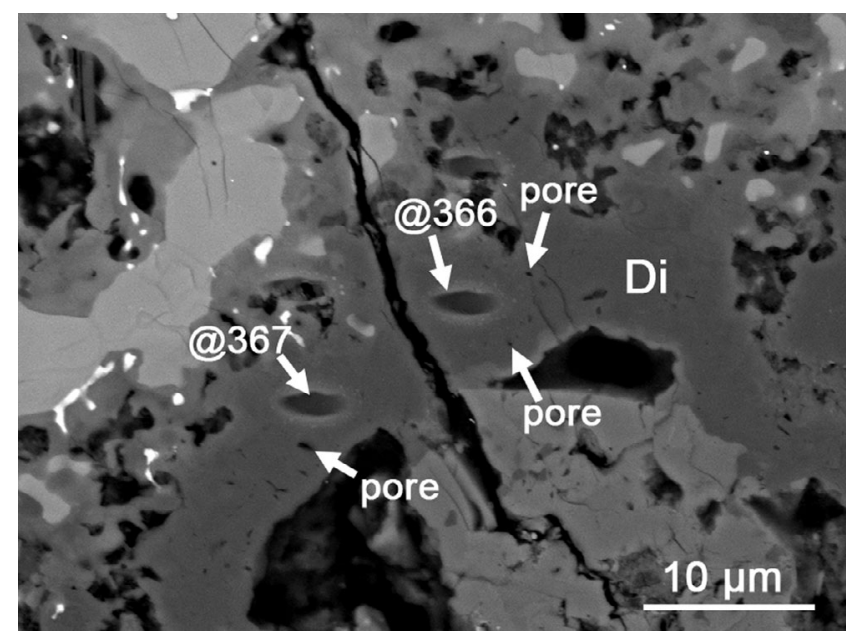

Fig. 13. BSE image showing the locations of two SIMS spots (@366 and@367) on Al-rich diopside in the rim. Note that pores are commonly present in the rim. $\mathrm{Di}=$ Al-rich diopside.

and Haneda 1996). Currently, no self-diffusion coefficient is available for davisite, but the oxygen selfdiffusion is normally slow in pyroxene (Farver 2010 and references therein). The davisite has porous aggregate texture and the grain size is smaller than perovskite, typically a few micrometers in size or less. The texture might not be directly formed by condensation but by aqueous alteration on the parent body. If so, crystal growth in the fluid might have reset the oxygen isotope signature to ${ }^{16} \mathrm{O}$-poor. The crystal sizes of Al-rich diopside are several micrometers and the Al-rich diopside layer is very thin with abundant pores. The diffusion, dissolution, and grain growth mechanism (Nakamura et al. 2005) might also be developed in the Al-rich diopside layer. As a result, the Al-rich diopside grains became moderately ${ }^{16} \mathrm{O}$-depleted to various degrees.

\section{CONCLUSIONS}

We performed a detailed petrological, mineralogical, and SIMS oxygen isotope analysis on an ultrarefractory inclusion CAI 007 from the CV chondrite NWA 3118.

1. The unique $\mathrm{Zr}, \mathrm{Sc}, \mathrm{Y}$-rich mineral assemblage, enrichment of the most refractory REEs in perovskite, and layered texture indicate that CAI 007 in NWA 3118 is an ultrarefractory inclusion with a condensation origin.

2. The CAI 007 inclusion has experienced fluid-assisted metamorphism on the parent body. The evidence includes (1) Fe-enrichment in spinel and olivine; (2) exsolution lamellae and the presence of scheelite, troilite, gypsum, molybdenite in refractory metal nuggets; (3) the presence of zeolite, grossular, and 

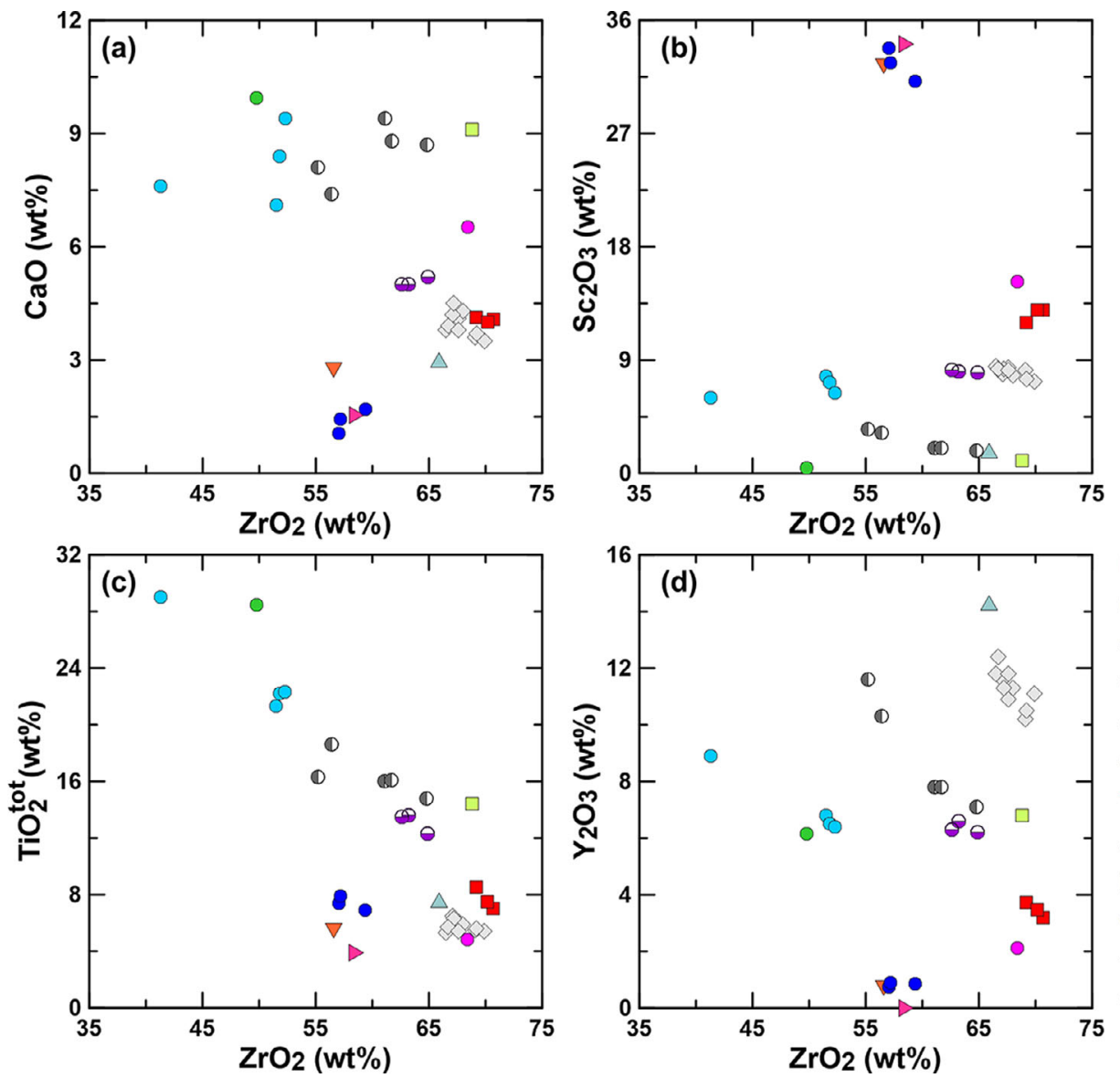

Clz in this study

$\mathrm{Clz}$ in Leoville (M-2020)

Tzr in this study

Tzr in 33E-1 (I-2012)

Tzr in Allende (M\&R-2008)

Tzr in Allende (M-2014)

Allendeite in Allende (M-2014)

$\mathrm{Zr}, \mathrm{Y}$-ox in Orans ( $\mathrm{N}-1977)$

Zr,Sc-ox in Acfer 182 (W\&B-1994)

$\mathrm{Zr}, \mathrm{Sc}-\mathrm{Ox}$ in 33E-1 (I-2012)

$\mathrm{Zr}, \mathrm{Sc}-\mathrm{ox} 1$ in $3 \mathrm{~N}-24$ (I-2012)

$\mathrm{Zr}, \mathrm{Sc}-\mathrm{ox} 2$ in $3 \mathrm{~N}-24$ (I-2012)

Fig. 14. Chemical compositions of the calzirtite and tazheranite in CAI 007 compared with other $\mathrm{Zr}$,Sc-rich oxide phases in ultrarefractory inclusions. M-2020 = Ma (2020); I-2012 = Ivanova et al. (2012); M-2014 = Ma et al. (2014); N-1977 = Noonan et al. (1977); W\&B-1994 = Weber and Bischoff (1994). (Color figure can be viewed at wileyonlinelibrary.com.)

potential nepheline; and (4) the intergrowth of calzirtite and tazheranite.

3. We have determined the chemistry and structure of the two $\mathrm{Zr}$,Sc-rich oxide phases in CAI 007, calzirtite and tazheranite. The calzirtite in CAI 007 is one of the $\mathrm{Zr}$-dominant refractory phases, while the tazheranite is one of the most Sc-rich phases in chondrites.

4. Minerals in the CAI 007 UR inclusion have different oxygen isotope compositions. Hibonite, spinel, and probably Al-rich diopside are ${ }^{16} \mathrm{O}$-rich $\left(\Delta^{17} \mathrm{O} \sim 22 \%\right.$ ) whereas perovskite and davisite are ${ }^{16} \mathrm{O}$-poor $\left(\Delta^{17} \mathrm{O} \sim 3 \%\right)$. Such oxygen isotope heterogeneity suggests that the UR inclusion formed in the various degrees of ${ }^{16} \mathrm{O}$-rich nebular setting or was originally ${ }^{16} \mathrm{O}$-rich and then experienced oxygen isotope exchange with ${ }^{16} \mathrm{O}$-poor fluid on the $\mathrm{CV} 3$ chondrite parent body.

Acknowledgments - We appreciate the editorial effort from Dr. Michael Zolensky and the helpful comments from Dr. Sasha Krot and Dr. Makoto Kimura, which improved the quality of the manuscript. We also thank Dr. Naotaka Tomioka for helpful discussion of identifying mineral phases under TEM and Dr. Juan Li for assistance during EBSD analysis. This work was financially supported by the B-type strategic Priority Program of the Chinese Academy of Sciences (Grant XDB41000000), a pre-research Project on Civil Aerospace Technologies funded by CNSA (Grant D020204), National Natural Science Foundation of China (Grant 41673068, 41973061), and the Natural Science Foundation of Jiangsu Province of China (Grant BK20170017).

Editorial Handling-Dr. Michael Zolensky

\section{REFERENCES}

Akos K., Szivia O., Sandor J., Mate S., and Maria T. 2014. Analysis of ripple or flow-like features in NWA 3118 CV3 meteorite. Planetary and Space Science 104:200-210. 
Boynton W. V. 1975. Fractionation in the solar nebula: Condensation of yttrium and the rare earth elements. Geochimica et Cosmochimica Acta 39:569-584.

Brearley A. J. and Krot A. N. 2013. Metasomatism in the early solar system: The record from chondritic meteorites. In Metasomatism and the chemical transformation of rock: The role of fluids in terrestrial and extraterrestrial processes, edited by Harlov D. and Austrheim $\mathrm{H}$. Heidelberg: Springer. pp. 659-789.

Clayton R. N. 2002. Solar system: Self-shielding in the solar nebula. Nature 415:860-861.

Clayton R. N. 2003. Isotopic self-shielding of oxygen and nitrogen in the solar nebula. Geochimica et Cosmochimica Acta 67:68.

Clayton R. N., Onuma N., Grossman L., and Mayeda T. K. 1977. Distribution of the pre-solar component in Allende and other carbonaceous chondrites. Earth and Planetary Science Letters 34:209-224.

Connelly J. N., Bizzarro M., Krot A. N., Nordlund A., Wielandt D., and Ivanova M. A. 2012. The absolute chronology and thermal processing of solids in the solar protoplanetary disk. Science 338:651-655.

El Goresy A., Nagel K., and Ramdohr P. 1978. Fremdlinge and their noble relatives. Proceedings, 9th Lunar and Planetary Science Conference. pp. 1279-1303.

El Goresy A., Zinner E., Marsunami S., Palme H., Spettel B., Lin Y., and Nazarov M. A. 2002. Efremovka 101.1: A CAI with ultrarefractory REE patterns and enormous enrichments of $\mathrm{Sc}, \mathrm{Zr}$, and $\mathrm{Y}$ in fassaite and perovskite. Geochimica et Cosmochimica Acta 66:1459-1491.

Farver J. R. 2010. Oxygen and hydrogen diffusion in minerals. Reviews in Mineralogy \& Geochemistry 72:447-507.

Fegley B. and Palme H. 1985. Evidence for oxidizing conditions in the solar nebula from Mo and $\mathrm{W}$ depletions in refractory inclusions in carbonaceous chondrites. Earth and Planetary Science Letters 72:311-326.

Genzel P. T., Bazi B., De Pauw E., Vekemans B., Vincze L., Garrevoet J., Lindner M., Falkenberg G., Ivanova M. A., Ma C., Davis A. M., Krot A. N., and Brenker F. E. 2020. Rare earth element analysis of UR CAIs from CV3 chondrites by SRXRF (abstract \#2002). 51st Lunar and Planetary Science Conference. CD-ROM.

Grossman L., Beckett J. R., Fedkin A. V., Simon S. B., and Ciesla F. J. 2008. Redox conditions in the solar nebula: Observational, experimental, and theoretical constraints. Reviews in Mineralogy \& Geochemistry 68:93-144.

Han J., Brearley A. J., and Keller L. P. 2015. Microstructural evidence for a disequilibrium condensation origin for hibonite-spinel inclusions in the ALHA77307 CO3.0 chondrite. Meteoritics \& Planetary Science 50:2121-2136.

Hsu W., Guan Y., Hua X., Wang Y., Leshin L. A., and Sharp T. G. 2006. Aqueous alteration of opaque assemblages in the Ningqiang carbonaceous chondrite: Evidence from oxygen isotopes. Earth and Planetary Science Letters 243:107-114.

Hu J. Y., Dauphas N., Tissot F. L. H., Davis A. M., Ciesla F., Yokochi R., and Ireland T. J. 2020. Stable isotopic fractionations of 8 REEs in group II CAIs and insights into early solar system evolution (abstract \#1631). 51st Lunar and Planetary Science Conference. CD-ROM.

Ivanova M. A., Krot A. N., Nagashima K., and MacPherson G. J. 2012. Compound ultrarefractory CAI-bearing inclusions from CV3 carbonaceous chondrites. Meteoritics \& Planetary Science 47:2107-2127.
Ivanova M. A., Lorenz C. A., Krot A. N., and MacPherson G. J. 2015. A compound Ca-, Al-rich inclusion from CV3 chondrite Northwest Africa 3118: Implications for understanding process during CAI formation. Meteoritics \& Planetary Science 50:1512-1528.

Izawa M. R. M., Flemming R. L., King P. L., Peterson R. C., and McCausland P. J. A. 2010a. Mineralogical and spectroscopic investigation of the Tagish Lake carbonaceous chondrite by X-ray diffraction and infrared reflectance spectroscopy. Meteoritics \& Planetary Science 45:675-698.

Izawa M. R. M., King P. L., Flemming R. L., Peterson R. C., and McCausland P. J. A. 2010b. Mineralogical and spectroscopic investigation of enstatite chondrites by X-ray diffraction and infrared reflectance spectroscopy. Journal of Geophysical Research Planets 115:E07008.

Katayama J., Itoh S., and Yurimoto H. 2012. Oxygen isotopic zoning of reversely zoned melilite crystals in a fluffy type A Ca-Al-rich inclusion from the Vigarano meteorite. Meteoritics \& Planetary Science 47:2094-2106.

Kawasaki N., Sakamoto N., and Yurimoto H. 2012. Oxygen isotopic and chemical zoning of melilite crystals in a Type A Ca-Al-rich inclusion of Efremovka CV3 chondrite. Meteoritics \& Planetary Science 47:2084-2093.

Kawasaki N., Kato C., Itoh S., Wakaki S., Ito M., and Yurimoto H. 2015. ${ }^{26} \mathrm{Al}-{ }^{26} \mathrm{Mg}$ chronology and oxygen isotope distributions of multiple melting for a Type C CAI from Allende. Geochimica et Cosmochimica Acta 169:99_ 114.

Kawasaki N., Itoh S., Sakamoto N., and Yurimoto H. 2017. Chronological study of oxygen isotope composition for the solar protoplanetary disk recorded in a fluffy Type A CAI from Vigarano. Geochimica et Cosmochimica Acta 201:83102.

Kawasaki N., Simon S. B., Grossman L., Sakamoto N., and Yurimoto H. 2018. Crystal growth and disequilibrium distribution of oxygen isotopes in an igneous Ca-Al-rich inclusion from the Allende carbonaceous chondrite. Geochimica et Cosmochimica Acta 221:318-341.

Komatsu M., Fagan T. J., Krot A. N., Nagashima K., Petaev M. I., Kimura M., and Yamaguchi A. 2018. First evidence for silica condensation within the solar protoplanetary disk. Proceedings of the National Academy of Sciences of the United States of America 115:7497-7502.

Krot A. N., Scott E. R. D., and Zolensky M. E. 1995. Mineralogical and chemical modification of components in CV3 chondrites: Nebular or asteroidal processing? Meteoritics 30:748-775.

Krot A. N., Petaev M. I., Zolensky M. E., Keil K., Scott E. R. D., and Nakamura K. 1998a. Secondary calcium-ironrich minerals in the Bali-like and Allende-like oxidized CV3 chondrites and Allende dark inclusions. Meteoritics \& Planetary Science 33:623-645.

Krot A. N., Petaev M. I., Scott E. R. D., Choi B. G., Zolensky M. E., and Keil K. 1998b. Progressive alteration in CV3 chondrites: More evidence for asteroidal alteration. Meteoritics \& Planetary Science 33:1065-1085.

Krot A. N., Nagashima K., and Petaev M. I. 2012. Isotopically uniform, ${ }^{16} \mathrm{O}$-depleted calcium, aluminum-rich inclusions in $\mathrm{CH}$ and $\mathrm{CB}$ carbonaceous chondrites. Geochimica et Cosmochimica Acta 83:159-178.

Krot A. N., Ma C., Nagashima K., Davis A. M., Beckett J. R., Simon S. B., Komatsu M., Fagan T. J., Brenker F., Ivanova M. A., and Bischoff A. 2019a. Mineralogy, 
petrography, and oxygen isotopic compositions of ultrarefractory inclusions from carbonaceous chondrites. Geochemistry 79:125519.

Krot A. N., Nagashima K., Fintor K., and Pál-Molnár E. 2019b. Evidence for oxygen-isotope exchange in refractory inclusions from Kaba (CV3.1) carbonaceous chondrite during fluid-rock interaction on the $\mathrm{CV}$ parent asteroid. Geochimica et Cosmochimica Acta 246:419-435.

Lee M. R. 1993. The petrography, mineralogy and origins of calcium-sulfate within the Cold Bokkeveld CM carbonaceous chondrite. Meteoritics 28:53-62.

Li Y., Zhang A. C., Chen J. N., Gu L. X., and Wang R. C. 2017. Formation of phosphorus-rich olivine in Dar al Gani 978 carbonaceous chondrite through fluid-assisted metamorphism. American Mineralogist 102:98-107.

Lodders K. 2003. Solar system abundances and condensation temperatures of the elements. The Astrophysical Journal 591:1220-1247.

Lyons J. R. and Young E. D. 2005. Photochemical speciation of oxygen isotopes in the solar nebula. Chondrites and the Protoplanetary Disk 341:193-211.

Ma C. 2019. Discovery of kaitianite, $\mathrm{Ti}^{3+}{ }_{2} \mathrm{Ti}^{4+} \mathrm{O}_{5}$, in Allende: A new refractory mineral from the solar nebula. Meteoritics \& Planetary Science 54:6098.

Ma C. 2020. Discovery of meteoritic calzirtite in Leoville: A new ultrarefractory phase from the solar nebula. Goldschmidt Abstract 1674.

Ma C. and Rossman G. R. 2008. Discovery of tazheranite (cubic zirconia) in the Allende meteorite. Geochimica et Cosmochimica Acta Supplement 72:A577.

Ma C. and Rossman G. R. 2009a. Tistarite, $\mathrm{Ti}_{2} \mathrm{O}_{3}$, a new refractory mineral from the Allende meteorite. American Mineralogist 94:841-844.

Ma C. and Rossman G. R. 2009b. Grossmanite, $\mathrm{CaTi}^{3+} \mathrm{AlSiO}_{6}$, a new pyroxene from the Allende meteorite. American Mineralogist 94:1491-1494.

Ma C., Tschauner O., Beckett J. R., Rossman G., and Liu W. 2013. Kangite, (Sc, Ti, Al, $\mathrm{Zr}, \mathrm{Mg}, \mathrm{Ca}, \square)_{2} \mathrm{O}_{3}$, a new ultrarefractory scandia mineral from the Allende meteorite: synchrotron micro-Laue diffraction and electron backscatter diffraction. American Mineralogist 98:870-878.

Ma C., Beckett J. R., and Rossman G. 2014. Allendeite, $\left(\mathrm{Sc}_{4} \mathrm{Zr}_{4} \mathrm{O}_{12}\right)$, and hexamolybdenum $(\mathrm{Mo}, \mathrm{Ru}, \mathrm{Fe})$, two new minerals from an ultrarefractory inclusion from the Allende meteorite. American Mineralogist 99:654-666.

Ma C., Yoshizaki T., Krot A. N., Beckett J. R., Nakamura T., Nagashima K., Muto J., and Ivanova M. A. 2017. Discovery of rubinite, $\mathrm{Ca}_{3} \mathrm{Ti}^{3+}{ }_{2} \mathrm{Si}_{3} \mathrm{O}_{12}$, a new garnet mineral in refractory inclusions from carbonaceous chondrites. Meteoritics \& Planetary Science 52:6023.

Ma C., Krot A. N., Beckett J. R., Nagashima K., Tschauner O., Rossman G. R., Simon S. B., and Bischoff A. 2020. Warkite, $\mathrm{Ca}_{2} \mathrm{Sc}_{6} \mathrm{Al}_{6} \mathrm{O}_{20}$, a new mineral in carbonaceous chondrites and a key-stone phase in ultrarefractory inclusions from the solar nebula. Geochimica et Cosmochimica Acta 277:52-86.

MacPherson G. J., Wark D. A., and Armstrong J. T. 1988. Primitive material surviving in chondrites: Refractory inclusions. In Meteorites and the early solar system, edited by Kerridge J. F. and Matthews M. S. Tucson, Arizona: University of Arizona Press. pp. 746-807.

MacPherson G. J., Bullock E. S., Tenner T. J., Nakashima D., Kita N. T., Ivanova M. A., Krot A. N., Petaev M. I., and Jacobsen S. B. 2017. High precision Al-Mg systematics of forsterite-bearing type B CAIs from CV3 chondrites. Geochimica et Cosmochimica Acta 201:65-82.

Marrocchi Y., Chaussidon M., Piani L., and Libourel G. 2016. Early scattering of the solar protoplanetary disk recorded in meteoritic chondrules. Science Advances 2: e1601001.

Mason B. and Martin M. 1977. Geochemical differences among components of the Allende meteorite. Smithsonian Contribution to the Earth Science 19:84-95.

Matsuda N., Sakamoto N., Tachibana S., and Yurimoto H. 2019. Heating duration of igneous rim formation on a chondrule in the Northwest Africa 3118 CV3oxA carbonaceous chondrite inferred from microscale migration of the oxygen isotopes. Geochemistry 79:25524.

McKeegan K. D., Kallio A. P. A., Heber V. S., Jarzebinski G., Mao P. H., Coath C. D., Kunihiro T., Wiens R. C., Nordholt J. E., Moses R. W. Jr., Reisenfeld D. B., Jurewicz A. J. G., and Burnett D. S. 2011. The oxygen isotopic composition of the Sun inferred from captured solar wind. Science 332:1528-1532.

Nakamura M., Yurimoto H., and Watson E. B. 2005. Grain growth control of isotope exchange between rocks and fluids. Geology 33:829-832.

Noonan A. F., Nelen J., Fredriksson K., and Newbury D. 1977. Zr-Y oxides and high-alkali glass in an amoeboid inclusion from Ornans (abstract). Meteoritics 12:32-335.

Palme H., Wlotzka F., Nagel K., and El Goresy A. 1982. An ultrarefractory inclusion from the Ornans carbonaceous chondrite. Earth and Planetary Science Letters 61:1-12.

Park C., Wakaki S., Sakamoto N., Kobayashi S., and Yurimoto H. 2012. Oxygen isotopic composition of the solar nebula gas inferred from high-precision isotope imaging of melilite crystals in an Allende CAI. Meteoritics \& Planetary Science 47:2070-2083.

Rubin A. E. and Ma C. 2017. Meteoritic minerals and their origins. Chemie der Erde 77:325-385.

Russell S. S., Zolensky M., Righter K., Folco L., Jones R., Connolly H. C. Jr., Grady M. M., and Grossman J. N. 2005. The Meteoritical Bulletin, No. 89. Meteoritics \& Planetary Science 40:A201-A263.

Sakaguchi I. and Haneda H. 1996. Oxygen tracer diffusion in single-crystal $\mathrm{CaTiO}_{3}$. Journal of Solid State Chemistry 124:195-197.

Sakamoto N., Seto Y., Itoh S., Kuramoto K., Fujino K., Nagashima K., Krot A. N., and Yurimoto H. 2007. Remnants of the early solar system water enriched in heavy oxygen isotopes. Science 317:231-233.

Simon J. I., Hutcheon I. D., Simon S. B., Matzel J. E. P., Ramon E. C., Weber P. K., Grossman L., and DePaolo D. J. 2011. Oxygen isotope variations at the margin of a CAI records circulation within the solar nebula. Science 331:1175-1178.

Simon S. B. and Grossman L. 2006. A comparative study of melilite and fassaite in types B1 and B2 refractory inclusions. Geochimica et Cosmochimica Acta 70:780-798.

Simon S. B., Davis A. M., and Grossman L. 1996. A unique ultrarefractory inclusion from the Murchison meteorite. Meteoritics \& Planetary Science 31:106-115.

Simon S. B., Sutton S. R., and Grossman L. 2007. Valence of titanium and vanadium in pyroxene in refractory inclusion interiors and rims. Geochimica et Cosmochimica Acta 71:3098-3118.

Simon S. B., Joswiak D. J., Ishii H. A., Bradley J. P., Chi M., Grossman L., Aléon J., Brownlee D. E., Fallon S., 
Hutcheon I. D., Matrajt G., and McKeegan K. D. 2008. A refractory inclusion returned by Stardust from comet 81P/Wild 2. Meteoritics \& Planetary Science 43:1861-1877.

Simon S. B., Grossman L., and Sutton S. R. 2012. Comment on "Valence state of titanium in the Wark-Lovering rim of a Leoville CAI as a record of progressive oxidation in the early Solar Nebula" by K. A. Dyl, J. I. Simon and E. D. Young. Geochimica et Cosmochimica Acta 85:373-376.

Simon S. B., Krot A. N., Nagashima K., Kööp L., and Davis A. M. 2019. Condensate refractory inclusions from the CO3.00 chondrite Dominion Range 08006: Petrography, mineral chemistry, and isotopic compositions. Geochimica et Cosmochimica Acta 246:109-122.

Ushikubo T., Hiyagon H., Hashimoto A., and Kimura M. 2004. Oxygen isotopic composition and REE abundances of a Zr-rich-oxide-bearing inclusion from Murchison (abstract \#5111). Meteoritics \& Planetary Science 39:A107.

Wasson J. T., Yurimoto H., and Russell S. S. 2001. ${ }^{16} \mathrm{O}$-rich melilite in CO3.0 chondrites: Possible formation of common, ${ }^{16} \mathrm{O}$-poor melilite by aqueous alteration. Geochimica et Cosmochimica Acta 65:4539-4549.

Weber D. and Bischoff A. 1994. The occurrence of grossite $\left(\mathrm{CaAl}_{4} \mathrm{O}_{7}\right)$ in chondrites. Geochimica et Cosmochimica Acta 58:3855-3877.

Wlotzka F. 1993. A weathering scale for the ordinary chondrites. Meteoritics 28:460.

Yoshizaki T., Nakashima D., Nakamura T., Park C., Sakamoto N., Ishida H., and Itoh S. 2019. Nebular history of an ultrarefractory phase bearing CAI from a reduced type $\mathrm{CV}$ chondrite. Geochimica et Cosmochimica Acta 252:39-60.

Yurimoto H. and Kuramoto K. 2004. Molecular cloud origin for the oxygen isotope heterogeneity in the solar system. Science 305:1763-1766.

Yurimoto H., Nagasawa H., Mori Y., and Matsubaya O. 1994. Micro-distribution of oxygen isotopes in a refractory inclusion from the Allende meteorite. Earth and Planetary Science Letters 128:47-53.

Yurimoto H., Ito M., and Nagasawa H. 1998. Oxygen isotope exchange between refractory inclusion in Allende and solar nebula gas. Science 282:1874-1877.

Yurimoto H., Krot A. N., Choi B. G., Aleon J., Kunihiro T., and Brearley A. J. 2008. Oxygen isotopes of chondritic components. Reviews in Mineralogy \& Geochemistry 68:141-187.

Zhang A. C. and Hsu W. B. 2009. Refractory inclusions and aluminum-rich chondrules in Sayh al Uhaymir $290 \mathrm{CH}$ chondrite: Petrography and mineralogy. Meteoritics \& Planetary Science 44:787-804.

Zhang A. C. and Yurimoto H. 2013. Petrography and mineralogy of the ungrouped type 3 carbonaceous chondrite Dar al Gani 978. Meteoritics \& Planetary Science 48:1651-1677.

Zhang A. C., Ma C., Sakamoto N., Wang R. C., Hsu W. B., and Yurimoto H. 2015. Mineralogical anatomy and implications of a $\mathrm{Ti}-\mathrm{Sc}$-rich ultrarefractory inclusion from Sayh al Uhaymir $290 \mathrm{CH} 3$ chondrite. Geochimica et Cosmochimica Acta 163:27-39. 